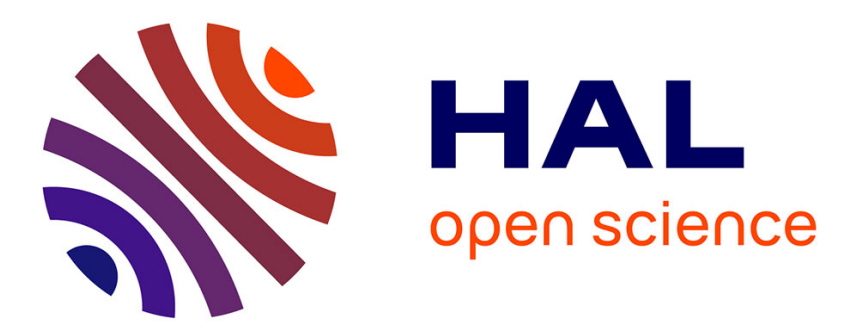

\title{
Low Temperature Synthesis and Phosphorescence of Methylcyanotriacetylene
}

Urszula Szczepaniak, Robert Kolos, Marcin Gronowski, Jean-Claude

Guillemin, Claudine Crépin

\section{- To cite this version:}

Urszula Szczepaniak, Robert Kolos, Marcin Gronowski, Jean-Claude Guillemin, Claudine Crépin. Low Temperature Synthesis and Phosphorescence of Methylcyanotriacetylene. Journal of Physical Chemistry A, 2018, 122 (1), pp.89-99. 10.1021/acs.jpca.7b09728 . hal-01696988

\section{HAL Id: hal-01696988 \\ https://hal-univ-rennes1.archives-ouvertes.fr/hal-01696988}

Submitted on 19 Mar 2018

HAL is a multi-disciplinary open access archive for the deposit and dissemination of scientific research documents, whether they are published or not. The documents may come from teaching and research institutions in France or abroad, or from public or private research centers.
L'archive ouverte pluridisciplinaire HAL, est destinée au dépôt et à la diffusion de documents scientifiques de niveau recherche, publiés ou non, émanant des établissements d'enseignement et de recherche français ou étrangers, des laboratoires publics ou privés. 


\title{
Low Temperature Synthesis and Phosphorescence of Methylcyanotriacetylene
}

Published as part of The Journal of Physical Chemistry virtual special issue "W. Lester S. Andrews Festschrift"

\author{
Urszula Szczepaniak $^{\mathrm{a}, \mathrm{b}}$ *, Robert Kołos ${ }^{\mathrm{b}}$, Marcin Gronowski $^{\mathrm{b}}$, Jean-Claude Guillemin ${ }^{\mathrm{c}}$, \\ and Claudine Crépin ${ }^{\mathrm{a}}$ \\ a Institut des Sciences Moléculaires d'Orsay (ISMO), UMR8214, CNRS, Univ. Paris-Sud, \\ Université Paris-Saclay, F-91405 Orsay, France \\ ${ }^{b}$ Institute of Physical Chemistry, Polish Academy of Sciences, Kasprzaka 44/52, PL-01-224 \\ Warsaw, Poland \\ ${ }^{\mathrm{c}}$ Institut des Sciences Chimiques de Rennes, École Nationale Supérieure de Chimie de Rennes, \\ CNRS, UMR 6226, 11 Allée de Beaulieu, CS 50837, 35708 Rennes Cedex 7, France \\ *e-mail : uszczepaniak@ichf.edu.pl,urszula.szczepaniak@u-psud.fr; Present address: Laboratory \\ of Physical Chemistry, ETH Zürich, Vladimir-Prelog Weg 2, CH-8093 Zürich, Switzerland
}




\begin{abstract}
This paper reports on UV-stimulated synthesis of methylcyanotriacetylene carried out in cryogenic rare gas matrices via coupling of smaller precursors: propyne and cyanodiacetylene. The detection was possible due to the strong visible $\boldsymbol{t}^{3} \mathrm{~A}^{\prime} \rightarrow X^{1} \mathrm{~A}_{1}$ phosphorescence of $\mathrm{CH}_{3} \mathrm{C}_{7} \mathrm{~N}$, discovered in the course of this work. The ensuing measurements of electronic spectroscopy revealed the formally forbidden $B{ }^{1} \mathrm{E}-\not{ }^{1} \mathrm{~A}_{1}$ system, as well as the allowed one $E^{1} \mathrm{~A}_{1}-X^{1} \mathrm{~A}_{1}$, with origins at approx. $3.32 \mathrm{eV}$ and $5.4 \mathrm{eV}$, respectively. It was also possible to revisit the spectroscopic characterization of cyanotriacetylene, $\mathrm{HC}_{7} \mathrm{~N}$, formed in parallel to the title photoproduct. Spectral assignments were assisted with a density functional theory study.
\end{abstract}




\section{INTRODUCTION}

The $\mathrm{H}(\mathrm{C} \equiv \mathrm{C})_{n} \mathrm{CN}$ molecules were observed with microwave spectroscopy, up to $n=4$, in diverse extra-terrestrial sources. ${ }^{1-6}$ Methylated cyanopolyacetylenes $\mathrm{CH}_{3}(\mathrm{C} \equiv \mathrm{C})_{n} \mathrm{CN}$ are also of astrochemical interest; methylcyanoacetylene, $\mathrm{CH}_{3} \mathrm{C}_{3} \mathrm{~N}$, was identified in the Taurus Molecular Cloud (TMC) ${ }^{7}$ and more recently in the Sagittarius B2 cloud near the Galactic center. ${ }^{8}$ The presence of methylcyanodiacetylene, $\mathrm{CH}_{3} \mathrm{C}_{5} \mathrm{~N}$, in TMC has also been confirmed. ${ }^{9,10}$, This latter compound appears, along with $\mathrm{CH}_{3} \mathrm{C}_{3} \mathrm{~N}$ and $\mathrm{CH}_{3} \mathrm{C}_{7} \mathrm{~N}$, in astrochemical kinetic models. ${ }^{10-13}$ It may originate, according to Quan and Herbst, ${ }^{10}$ from the dissociative recombination of $\mathrm{CH}_{3} \mathrm{C}_{5} \mathrm{NH}^{+}$cations with electrons or from the encounter of neutral species $\mathrm{CN}$ and $\mathrm{CH}_{3} \mathrm{C}_{4} \mathrm{H}$. Markwick et al. ${ }^{12}$ considered the reaction of $\mathrm{HC}_{5} \mathrm{~N}$ with $\mathrm{CH}_{3} \mathrm{OH}_{2}{ }^{+} . \mathrm{CH}_{3} \mathrm{C}_{3} \mathrm{~N}$ was also included in modelling of Titan's atmosphere ${ }^{14,15}$, and indeed the mass-spectrometric data from Cassini spacecraft suggested the presence of both $\mathrm{CH}_{3} \mathrm{C}_{3} \mathrm{~N}$ and $\mathrm{CH}_{3} \mathrm{C}_{5} \mathrm{~N}^{14}$

Addition of a methyl group to a cyanopolyacetylenic chain changes its physical properties. For example, we could see partial thermal decomposition of $\mathrm{HC}_{5} \mathrm{~N}$ occurring even at $-78^{\circ} \mathrm{C}$, while the methylated analogue, $\mathrm{CH}_{3} \mathrm{C}_{5} \mathrm{~N}$, remains stable at least its melting point $\left(92^{\circ} \mathrm{C}^{16}\right)$. The same trend was observed by us for $\mathrm{HC}_{3} \mathrm{~N}$ and $\mathrm{CH}_{3} \mathrm{C}_{3} \mathrm{~N}$ : at room temperature, the condensed phase of the latter is stable while the former decomposes and has to be stored below $-20^{\circ} \mathrm{C}$.

The smallest of methylcyanopolyacetylenes, $\mathrm{CH}_{3} \mathrm{C}_{3} \mathrm{~N}$, has been the subject of numerous spectroscopic investigations. ${ }^{17-24}$ For $\mathrm{CH}_{3} \mathrm{C}_{5} \mathrm{~N}$, the next member of the series, gas-phase rotational transitions ${ }^{25,26}$ and infrared absorption ${ }^{27}$ were reported, as well as vibrational ${ }^{28}$ and electronic $^{29}$ spectra of pure solid and of rare gas matrix-isolated compound. It was reported that photolysis of $\mathrm{CH}_{3} \mathrm{C} \equiv \mathrm{CH}$ (propyne) mixed with cyanoacetylene leads to $\mathrm{CH}_{3} \mathrm{C}_{5} \mathrm{~N} .{ }^{16}$ Kerisit et al. ${ }^{30}$ 
suggested that $\mathrm{CH}_{3} \mathrm{C}_{7} \mathrm{~N}$ might analogously form in photochemical reactions involving gaseous $\mathrm{CH}_{3} \mathrm{C} \equiv \mathrm{C}-\mathrm{C} \equiv \mathrm{CH}\left(1,3-\right.$ pentadiyne) and $\mathrm{HC}_{3} \mathrm{~N}$ precursors (the identification was based on a single ${ }^{1} \mathrm{H}$ NMR peak).

The first report to mention $\mathrm{CH}_{3} \mathrm{C}_{7} \mathrm{~N}$ (methylcyanotriacetylene, 6-methyl-1-cyanohexa-1,3,5triyne, octa-2,4,6-triynenitrile) discussed its difficult synthesis, and provided infrared, as well as UV absorption spectra (for an ether solution). ${ }^{31}$ Microwave transitions were subsequently investigated. $^{26,32,33}$ Theoretical results are available for rotational constants, molecular geometry, polarizability, and electric dipole moment. ${ }^{34,35}$

Our earlier studies ${ }^{36-38}$ demonstrated the appearance of mono- and dicyanopolyacetylenes in cryogenic UV-stimulated processes, out of shorter $\mathrm{H}(\mathrm{C} \equiv \mathrm{C})_{n} \mathrm{CN}$ species reacting with one another or with acetylenic-type molecules $\mathrm{H}(\mathrm{C} \equiv \mathrm{C})_{m} \mathrm{H}$. Such syntheses have already been shown to work for cyanodiacetylene $\left(\mathrm{HC}_{5} \mathrm{~N}\right),{ }^{36,38}$ cyanotriacetylene $\left(\mathrm{HC}_{7} \mathrm{~N}\right),{ }^{37}$ and cyanotetraacetylene $\left(\mathrm{HC}_{9} \mathrm{~N}\right) .{ }^{39}$ In particular, $\mathrm{HC}_{7} \mathrm{~N}$ was detected in $\mathrm{UV}$-irradiated $\left(\mathrm{H}_{2}\right.$ discharge lamp or $193 \mathrm{~nm}$ laser) solid Ar doped with either $\mathrm{HC}_{3} \mathrm{~N}+\mathrm{C}_{4} \mathrm{H}_{2}$ or $\mathrm{HC}_{5} \mathrm{~N}+\mathrm{C}_{2} \mathrm{H}_{2}$ mixture. ${ }^{37} \mathrm{HC}_{7} \mathrm{~N}$ was also produced by electric discharges in a $\mathrm{HC}_{3} \mathrm{~N} / \mathrm{Kr}$ mixture, prior to the trapping onto a cold substrate. ${ }^{40}$ In all these cryogenic approaches, the generated cyanopolyacetylenes were found to emit strong phosphorescence, which proved to be the most sensitive spectroscopic indicator of their presence. However, no photochemically-stimulated cryogenic synthesis has as yet been reported for any methylated cyanopolyacetylene. Here we aimed at verifying the utility of such an approach to the formation of $\mathrm{CH}_{3} \mathrm{C}_{7} \mathrm{~N}$ by coupling the precursors $\mathrm{CH}_{3} \mathrm{C}_{2} \mathrm{H}$ and $\mathrm{HC}_{5} \mathrm{~N}$. Propyne, similarly to $\mathrm{HC}_{5} \mathrm{~N}$, features an easily photodetachable acetylenic hydrogen atom. ${ }^{41,42}$ The targeted molecule has indeed appeared along with $\mathrm{HC}_{7} \mathrm{~N}$, offering an opportunity to compare 
the electronic transitions of the two closely related products and to extend the prior knowledge on UV-Vis absorption ${ }^{43-46}$ and low temperature phosphorescence ${ }^{37,40}$ of $\mathrm{HC}_{7} \mathrm{~N}$. Spectroscopic assignments were backed with density functional theory calculations of electronic and vibrational energy levels.

\section{METHODS}

\section{A. Experimental}

Propyne was commercially available from Aldrich (purity $>97 \%$ ). The second precursor, cyanodiacetylene, was prepared using the method developed by Trolez \& Guillemin. ${ }^{47}$ The compounds were purified before the experiments by pumping while kept at $\mathrm{T}<200 \mathrm{~K}\left(\mathrm{HC}_{5} \mathrm{~N}\right)$ or by several freeze-pump-thaw cycles with freezing at $\mathrm{T}<200 \mathrm{~K}\left(\mathrm{CH}_{3} \mathrm{C}_{2} \mathrm{H}\right)$.

Krypton (purity 4.0, Messer), mixed with the precursor chemicals, was trapped onto a sapphire substrate held at $30 \mathrm{~K}$ inside a closed-cycle helium cryostat. Photochemical transformations were induced with a $193 \mathrm{~nm}$ ArF excimer laser. All details concerning the experimental set-up and spectroscopic instrumentation were given in a paper by Szczepaniak et al. (this issue). ${ }^{39}$ Experiments were primarily aimed at identification of the created photoproducts and characterization of their electronic transitions, by measuring dispersed phosphorescence spectra, as well as phosphorescence excitation spectra, and phosphorescence lifetime.

An experiment involving $\mathrm{CH}_{3} \mathrm{C}_{2} \mathrm{H}+\mathrm{HC}_{3} \mathrm{~N}$ mixture $\left(\mathrm{HC}_{3} \mathrm{~N}\right.$ obtained following the Miller and Lemon ${ }^{48}$ method), expected to yield $\mathrm{CH}_{3} \mathrm{C}_{5} \mathrm{~N}$, was first performed to verify the validity of the applied approach. The test was positive; not only the phosphorescence of $\mathrm{CH}_{3} \mathrm{C}_{5} \mathrm{~N}$, but also that 


\begin{abstract}
of $\mathrm{HC}_{5} \mathrm{~N}$ could be detected in $\mathrm{Kr} / \mathrm{CH}_{3} \mathrm{C}_{2} \mathrm{H} / \mathrm{HC}_{3} \mathrm{~N}(1000 / 1 / 1)$ matrices previously subjected to 193 nm photolysis.
\end{abstract}

Two different gas mixtures were used in the main $\mathrm{CH}_{3} \mathrm{C}_{2} \mathrm{H}+\mathrm{HC}_{5} \mathrm{~N}$ experiment. Cyanodiacetylene was deposited in the amount either the same or twice smaller than that of propyne. The latter mixture $\left(\mathrm{Kr} / \mathrm{CH}_{3} \mathrm{C}_{2} \mathrm{H} / \mathrm{HC}_{5} \mathrm{~N}\right.$ ratio of $\left.1000 / 2 / 1\right)$ noticeably favored the formation of $\mathrm{CH}_{3} \mathrm{C}_{7} \mathrm{~N}$ over $\mathrm{HC}_{7} \mathrm{~N}$.

\title{
B. Computational details
}

Theoretical procedures applied here coincide with those described in more detail in a recent paper by Szczepaniak et al. ${ }^{39}$ GAUSSIAN 09 (Rev. B. 01) ${ }^{49}$ implementations of the density functional theory (DFT) ${ }^{50}$ were mostly applied. The B3PW91 ${ }^{51}$ functional was employed in the derivation of molecular geometries, harmonic vibrational frequencies, IR absorption intensities, and Raman activities for the ground and the lowest triplet state, while the time-dependent B3PW91 approach served for predicting transitions from the ground to excited singlet electronic states. Basis set aug-cc-pVTZ ${ }^{52,53}$ was applied in all these computations.

Geometry optimizations carried out for excited singlet states of $\mathrm{CH}_{3} \mathrm{C}_{7} \mathrm{~N}$ led to the structures (genuine potential energy minima) very slightly deviating from the $\mathrm{C}_{3 \mathrm{v}}$ symmetry. Based on our former $\mathrm{CH}_{3} \mathrm{C}_{5} \mathrm{~N}$ study, ${ }^{29}$ we suppose this effect to be of a purely numerical nature.

Influence of the Herzberg-Teller effect on intensity of the vibronic $B^{1} \Delta-X^{1} \Sigma^{+}$transitions was estimated by carrying out oscillator strength calculations for a $\mathrm{HC}_{7} \mathrm{~N}$ molecule slightly distorted, mimicking, case by case, the effect of various bending vibrations. The distortion vector was 
always parallel to a respective normal coordinate and had a length of $0.1 \AA$. The coupling effect was considered as important when the described simulation produced a noticeable oscillator strength $(f \geq 0.0001)$.

\section{RESULTS AND DISCUSSION}

\section{A. Theoretical predictions}

Despite obviously different molecular symmetries, $\mathrm{HC}_{5} \mathrm{~N}$ and $\mathrm{CH}_{3} \mathrm{C}_{5} \mathrm{~N}$ exhibit strikingly alike electronic spectra, as noticed by Turowski et al. ${ }^{29}$ Such similarities, stemming from closely related chromophores, were expected also for the $\mathrm{HC}_{7} \mathrm{~N} / \mathrm{CH}_{3} \mathrm{C}_{7} \mathrm{~N}$ pair. Quantum chemical predictions for the lowest electronic energy levels of $\mathrm{HC}_{7} \mathrm{~N}$ and $\mathrm{CH}_{3} \mathrm{C}_{7} \mathrm{~N}$ are presented in Table 1; general patterns of electronic state distribution are indeed very similar for both species. Nevertheless, the states arising from HOMO-LUMO electronic excitations have slightly higher energies for $\mathrm{HC}_{7} \mathrm{~N}$ than for $\mathrm{CH}_{3} \mathrm{C}_{7} \mathrm{~N}$ (resembling what was observed for $\mathrm{HC}_{5} \mathrm{~N}$ and $\mathrm{CH}_{3} \mathrm{C}_{5} \mathrm{~N}$ ). ${ }^{29}$ For both molecules, $\mathbb{E}-\not$ is predicted as the strongest transition. The expected $a-X$ transition energy of $\mathrm{CH}_{3} \mathrm{C}_{7} \mathrm{~N}(2.23 \mathrm{eV})$ is practically identical to that of $\mathrm{HC}_{7} \mathrm{~N}(2.25 \mathrm{eV})$, just as previously calculated and measured for $\mathrm{CH}_{3} \mathrm{C}_{5} \mathrm{~N}$ and $\mathrm{HC}_{5} \mathrm{~N}(2.90 \mathrm{eV}$ vs. $2.92 \mathrm{eV}$ at CAM-B3LYP/aug-ccpVTZ level of theory, 2.94 vs. $2.92 \mathrm{eV}$ in Ar matrix). ${ }^{29}$ 
Table 1. Energy $[\mathrm{eV}]$, wavelength $[\mathrm{nm}]$, and oscillator strength for transitions involving the ground and excited electronic states of $\mathrm{HC}_{7} \mathrm{~N}$ and $\mathrm{CH}_{3} \mathrm{C}_{7} \mathrm{~N}$, as calculated at B3PW91/aug-cc-pVTZ level of theory. Electronic configurations of the molecules are the following. $\mathrm{HC}_{7} \mathrm{~N}, X^{1} \Sigma^{+}$: [core] $(1 \sigma)^{2}(2 \sigma)^{2}$ $(3 \sigma)^{2}(4 \sigma)^{2}(5 \sigma)^{2}(6 \sigma)^{2}(1 \pi)^{4}(7 \sigma)^{2}(2 \pi)^{4}(8 \sigma)^{2}(9 \sigma)^{2}(3 \pi)^{4}(4 \pi)^{4}\left(1 \pi^{*}\right)^{0}\left(2 \pi^{*}\right)^{0}\left(1 \sigma^{*}\right)^{0} ; C_{3} H_{3} C_{7} N, X^{*} A_{1}$ : [core] $\left(1 a_{1}\right)^{2}\left(2 a_{1}\right)^{2}\left(3 a_{1}\right)^{2}\left(4 a_{1}\right)^{2}\left(5 a_{1}\right)^{2}\left(6 a_{1}\right)^{2}\left(7 a_{1}\right)^{2}(1 e)^{4}(2 e)^{4}\left(8 a_{1}\right)^{2}(3 e)^{4}(4 e)^{4}(5 e)^{4}\left(1 e^{*}\right)^{0}\left(1 a_{1}^{*}\right)^{0}\left(2 e^{*}\right)^{0}$.

\begin{tabular}{|c|c|c|c|c|c|c|c|c|c|}
\hline \multicolumn{5}{|c|}{$\mathrm{HC}_{7} \mathrm{~N}$} & \multicolumn{5}{|c|}{$\mathrm{CH}_{3} \mathrm{C}_{7} \mathrm{~N}$} \\
\hline State & $\begin{array}{c}\text { Dominant } \\
\text { orbital } \\
\text { excitation }\end{array}$ & $\begin{array}{c}\text { Vertical } \\
\text { energy } \\
(\lambda)\end{array}$ & $f^{a}$ & $\begin{array}{c}0-0 \\
\text { transition } \\
\text { energy } \\
(\lambda)\end{array}$ & State & $\begin{array}{l}\text { Dominant } \\
\text { orbital } \\
\text { excitation }\end{array}$ & $\begin{array}{c}\text { Vertical } \\
\text { energy } \\
(\lambda)\end{array}$ & $f^{a}$ & $\begin{array}{c}0-0 \\
\text { transition } \\
\text { energy }^{c} \\
(\lambda)\end{array}$ \\
\hline$A^{1} \Sigma^{-}$ & $4 \pi \rightarrow 1 \pi^{*}$ & $\begin{array}{c}3.29 \\
(377)\end{array}$ & 0 & $\begin{array}{c}2.84 \\
(437) \\
\end{array}$ & $A^{1} \mathrm{~A}_{2}$ & $5 \mathrm{e} \rightarrow 1 \mathrm{e}^{*}$ & $\begin{array}{c}3.23 \\
(384)\end{array}$ & 0 & $\begin{array}{c}2.75 \\
(451) \\
\end{array}$ \\
\hline$B^{1} \Delta$ & $4 \pi \rightarrow 1 \pi^{*}$ & $\begin{array}{c}3.40 \\
(365)\end{array}$ & 0 & $\begin{array}{c}2.96 \\
(419)\end{array}$ & $B^{1} \mathrm{E}$ & $5 \mathrm{e} \rightarrow 1 \mathrm{e}^{*}$ & $\begin{array}{c}3.34 \\
(371)\end{array}$ & 0 & $\begin{array}{c}2.9 \\
(428)\end{array}$ \\
\hline$\sigma^{1} \Sigma^{-}$ & $3 \pi \rightarrow 1 \pi^{*}$ & $\begin{array}{c}5.10 \\
(243)\end{array}$ & 0 & $\begin{array}{c}4.79 \\
(259)\end{array}$ & $\sigma^{1} \mathrm{~A}_{2}$ & $4 \mathrm{e} \rightarrow 1 \mathrm{e}^{*}$ & $\begin{array}{c}5.05 \\
(246)\end{array}$ & 0 & $\begin{array}{c}4.73 \\
(262)\end{array}$ \\
\hline$\theta^{1} \Delta$ & $3 \pi \rightarrow 1 \pi^{*}$ & $\begin{array}{c}5.27 \\
(235)\end{array}$ & 0 & $\begin{array}{l}4.98 \\
(249)\end{array}$ & $D^{1} \mathrm{E}$ & $4 \mathrm{e} \rightarrow 1 \mathrm{e}^{*}$ & $\begin{array}{c}5.22 \\
(238)\end{array}$ & 0.0001 & $\begin{array}{l}4.92 \\
(252)\end{array}$ \\
\hline \multirow[t]{3}{*}{$E^{1} \Sigma^{+}$} & $4 \pi \rightarrow 1 \pi^{*}$ & $\begin{array}{c}5.84 \\
(212) \\
\end{array}$ & 2.9 & $\begin{array}{c}5.63 \\
(220) \\
\end{array}$ & $E^{1} \mathrm{~A}_{1}$ & $5 \mathrm{e} \rightarrow 1 \mathrm{e}^{*}$ & $\begin{array}{c}5.61 \\
(221)\end{array}$ & 2.9 & $\begin{array}{c}5.40 \\
(230)\end{array}$ \\
\hline & & & & & $F^{1} \mathrm{E}$ & $5 \mathrm{e} \rightarrow 1 \mathrm{a}_{1}{ }^{*}$ & $\begin{array}{c}6.18 \\
(201)\end{array}$ & 0 & \\
\hline & & & & & $G^{1} \mathrm{~A}_{2}$ & $5 \mathrm{e} \rightarrow 2 \mathrm{e}^{*}$ & $\begin{array}{c}6.2 \\
(200)\end{array}$ & 0 & \\
\hline \multirow[t]{2}{*}{$F^{1} \Sigma^{+}$} & $3 \pi \rightarrow 1 \pi^{*}$ & $\begin{array}{c}6.23 \\
(199)\end{array}$ & 0.78 & $\begin{array}{c}5.86 \\
(212)\end{array}$ & $H^{1} \mathrm{~A}_{1}$ & $4 \mathrm{e} \rightarrow 1 \mathrm{e}^{*}$ & $\begin{array}{c}6.25 \\
(198)\end{array}$ & 1.2 & \\
\hline & & & & & $\tau^{1} \mathrm{E}$ & $5 \mathrm{e} \rightarrow 2 \mathrm{e}^{*}$ & $\begin{array}{c}6.25 \\
(198) \\
\end{array}$ & 0.0002 & \\
\hline $\boldsymbol{a}^{3} \Sigma^{+}$ & $4 \pi \rightarrow 1 \pi^{*}$ & & & $\begin{array}{c}2.25 \\
(551)\end{array}$ & $\boldsymbol{a}^{3} \mathrm{~A}^{, b}$ & $5 e \rightarrow 1 e^{*}$ & & & $\begin{array}{c}2.23 \\
(556)\end{array}$ \\
\hline
\end{tabular}

${ }^{a}$ Value of zero indicates $f<5 \cdot 10^{-5} .{ }^{b} C_{\mathrm{s}}$ geometry uncertain; $C_{3 \mathrm{v}}$ (leading to $\mathrm{A}_{1}$ triplet state symmetry) also possible, albeit less likely. ${ }^{c}$ Derivation of missing 0-0 energy entries was impeded by numerical problems (inherent to the applied method).

The nature of $\mathbb{E}-\not$ transitions is in both molecules similar to that of $\mathscr{A}-\not \mathbb{}$ or $\mathbb{B}-\not$, in the sense that they all involve mainly the HOMO-LUMO excitations. $\not-\not$ transitions (either $\Sigma^{-}-\Sigma^{+}$ or $\left.\mathrm{A}_{2}-\mathrm{A}_{1}\right)$ are formally not allowed for both molecules, while $B-\not x$, forbidden for $\mathrm{HC}_{7} \mathrm{~N}(\Delta-\Sigma)$ and formally allowed for $\mathrm{CH}_{3} \mathrm{C}_{7} \mathrm{~N}\left(\mathrm{E}-\mathrm{A}_{1}\right)$, is in fact effectively forbidden also for this latter molecule. One may nevertheless expect to see the $B-\not$ absorption of $\mathrm{CH}_{3} \mathrm{C}_{7} \mathrm{~N}$ due to the 
Herzberg-Teller vibronic coupling of electronic excitation with one of the vibrational bending modes, a phenomenon reported for shorter cyano- ${ }^{22,54,55}$ and methylcyanopolyacetylenes ${ }^{24,29}$. The Herzberg-Teller effect was supposed to occur if the electronic transition dipole moment significantly increased from its equilibrium value after distorting a molecule along a particular normal vibrational coordinate. In our simulations performed for $\mathrm{HC}_{7} \mathrm{~N}$ (see Computational details), only the $v_{10}$ mode coordinate produced such an effect. $\not-\not x$ bands are expected to have very low intensity; merely traces of that system were observed for $\mathrm{CH}_{3} \mathrm{C}_{5} \mathrm{~N}^{29}$ and for $\mathrm{HC}_{5} \mathrm{~N}^{55}$

Molecular geometries for the states $X, \mathbb{B}, \mathbb{E}$, and $\boldsymbol{a}$, involved in the experimentally explored electronic transitions of $\mathrm{HC}_{7} \mathrm{~N}$ and $\mathrm{CH}_{3} \mathrm{C}_{7} \mathrm{~N}$, are depicted in Figure 1 (predictions for the other states of Table 1 can be found in Figure S1). Ground-state $\mathrm{HC}_{7} \mathrm{~N}$ and $\mathrm{CH}_{3} \mathrm{C}_{7} \mathrm{~N}$ possess conjugated carbon-nitrogen backbones of closely similar geometries. Noteworthy, heavy-atom skeleton changes accompanying $\mathbb{B}-\not$ transition are, for both molecules, almost identical to those of $a-X$. One may therefore expect the main vibronic progressions in $B-X$ absorption and in phosphorescence spectra to be shaped by vibrational modes of similar nature, just as observed for the $\mathrm{HC}_{5} \mathrm{~N} / \mathrm{CH}_{3} \mathrm{C}_{5} \mathrm{~N}$ pair. ${ }^{29}$ Conversely, the geometry change occurring upon the transition from $X$ to $\mathbb{E}$ is much different from those characterizing $a-X^{x}$ or $B-\not X$.

It is worth noting that our optimizations of $\mathrm{CH}_{3} \mathrm{C}_{7} \mathrm{~N}$ geometry formally indicate, for the $\boldsymbol{\theta}$ state, the point group $C_{s}$, rather than $C_{3 v}$; the effect comes primarily from a small lowering of the $\mathrm{CH}_{3}$ group symmetry (see Figure 1). We currently cannot conclude whether this deviation from $C_{3 v}$ is or is not a numerical artifact. However, even if it were real, it would have not, (considering its magnitude) show up in the low-resolution spectra produced in this study. 


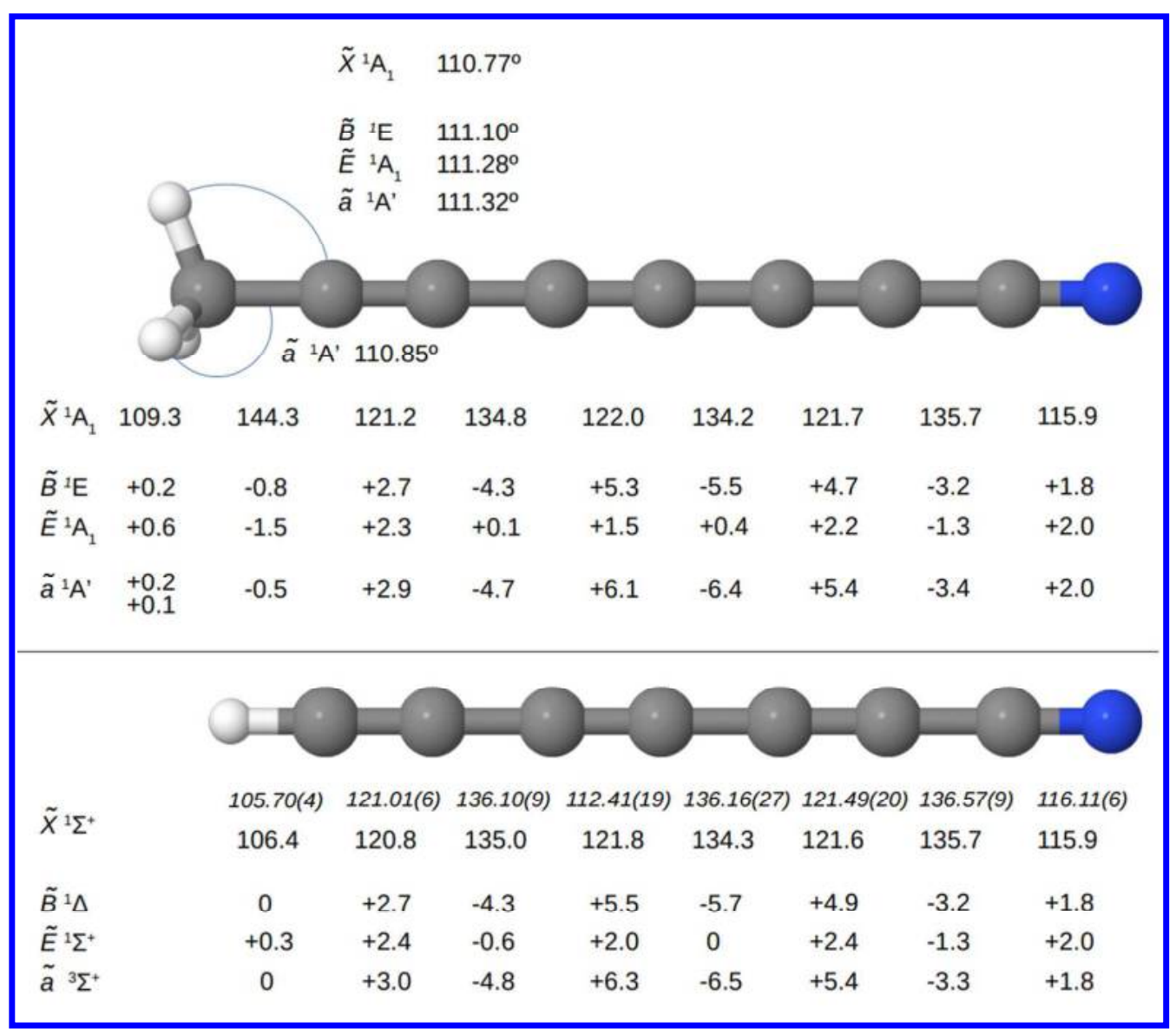

Figure 1. $\mathrm{CH}_{3} \mathrm{C}_{7} \mathrm{~N}$ and $\mathrm{HC}_{7} \mathrm{~N}$ geometry in the ground and excited electronic states, as derived at the B3PW91/aug-cc-pVTZ level of theory. Experimental parameters of $\mathrm{HC}_{7} \mathrm{~N}$ (in italics) are cited after McCarthy et al., Ref. 56. Interatomic distances in pm. Values listed for the excited electronic states are relative, calculated with respect to $\not x$. For higher electronic states, see Figure S1 of Supporting Information. 
Table 2. Harmonic wavenumbers of vibrational modes ( $*$; scaled by 0.96 ) for the ground and selected excited electronic states of $\mathrm{HC}_{7} \mathrm{~N}$ and $\mathrm{CH}_{3} \mathrm{C}_{7} \mathrm{~N}$, together with ground-state infrared intensities (IR) and Raman activities (R), as derived at the B3PW91/aug-cc-pVTZ level of theory. Mode symmetry descriptions refer strictly to the ground electronic states. See Tables S1 and S2 of the Supporting Information for the visualization of vibrations.

\begin{tabular}{|c|c|c|c|c|c|c|c|c|c|c|c|}
\hline \multirow{3}{*}{ Mode } & \multicolumn{5}{|c|}{$\mathrm{HC}_{7} \mathrm{~N}$} & & \multicolumn{4}{|c|}{$\mathrm{CH}_{3} \mathrm{C}_{7} \mathrm{~N}$} & \multirow{3}{*}{$\begin{array}{c}\mathbb{E} \\
\not{v} \\
\mathrm{~cm}^{-1}\end{array}$} \\
\hline & \multicolumn{3}{|c|}{$\not x$} & \multirow{2}{*}{$\begin{array}{c}B \\
\not \forall \boldsymbol{v} \\
\mathrm{cm}^{-1}\end{array}$} & \multirow{2}{*}{$\begin{array}{c}\mathbb{E} \\
\mathscr{V} \\
\mathrm{cm}^{-1}\end{array}$} & \multirow{2}{*}{ Mode } & \multicolumn{3}{|c|}{$X^{*}$} & \multirow{2}{*}{ 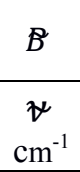 } & \\
\hline & $\begin{array}{c}\not{\forall} \\
\mathrm{cm}^{-1}\end{array}$ & $\begin{array}{c}I R \\
\mathrm{~km} / \mathrm{mol}\end{array}$ & $\begin{array}{c}R \\
\AA^{4} / \mathrm{amu}\end{array}$ & & & & $\begin{array}{c}\not{W} \\
\mathrm{~cm}^{-1}\end{array}$ & $\begin{array}{c}I R \\
\mathrm{~km} / \mathrm{mol}\end{array}$ & $\begin{array}{c}R \\
\AA^{4} / \mathrm{amu}\end{array}$ & & \\
\hline & \multicolumn{5}{|c|}{$\sigma$ symmetry } & & \multicolumn{4}{|c|}{$\mathrm{a}_{1}$ symmetry } & \\
\hline \multirow[t]{2}{*}{$v_{1}$} & 3324 & 156 & 18 & 3316 & 3290 & & & & & & \\
\hline & & & & & & $v_{1}$ & 2910 & 8.9 & 1223 & 2882 & 2841 \\
\hline$v_{2}$ & 2253 & 88 & 1600 & 2117 & 2172 & $v_{2}$ & 2260 & 7.9 & 100 & 2114 & 2180 \\
\hline$v_{3}$ & 2197 & 133 & 9800 & 2033 & 2073 & $v_{3}$ & 2208 & 410 & 10000 & 2038 & 2132 \\
\hline$v_{4}$ & 2154 & 5 & 1600 & 1907 & 1949 & $v_{4}$ & 2187 & 290 & 8500 & 1968 & 1969 \\
\hline \multirow[t]{3}{*}{$v_{5}$} & 2049 & 0 & 445 & 1819 & 1855 & $v_{5}$ & 2093 & 0.014 & 7.3 & 1848 & 1917 \\
\hline & & & & & & $v_{6}$ & 1364 & 1.3 & 89 & 1460 & 1323 \\
\hline & & & & & & $v_{7}$ & 1333 & 7.7 & 78 & 1332 & 1295 \\
\hline$v_{6}$ & 1295 & 0 & 24 & 1393 & 1252 & $v_{8}$ & 1066 & 0.7 & 13 & 1082 & 1061 \\
\hline$v_{7}$ & 902 & 3 & 0.41 & 926 & 884 & $v_{9}$ & 758 & 6.7 & 0.88 & 767 & 745 \\
\hline$v_{8}$ & 464 & 0 & 2.7 & 477 & 456 & $v_{10}$ & 402 & 1.0 & 1.9 & 412 & 395 \\
\hline \multicolumn{6}{|c|}{$\pi$ symmetry } & \multicolumn{6}{|c|}{ e symmetry } \\
\hline & & & & & & $v_{11}$ & 2976 & 1.9 & 370 & 2892 & 2894 \\
\hline & & & & & & $v_{12}$ & 1398 & 21 & 27 & 1384 & 1352 \\
\hline & & & & & & $v_{13}$ & 991 & 4.3 & 12 & 1022 & 953 \\
\hline$v_{9}$ & 643 & 80 & 14 & $522^{a}$ & 541 & & & & & & \\
\hline$v_{10}$ & 602 & 1 & 57 & $553^{a}$ & 517 & $v_{14}$ & 574 & 2.3 & 33 & 523 & 490 \\
\hline$v_{11}$ & 523 & 2 & 0.001 & 483 & 434 & $v_{15}$ & 518 & 4.4 & 0.092 & 476 & 437 \\
\hline \multirow[t]{2}{*}{$v_{12}$} & 461 & 10 & 4.0 & 434 & 412 & $v_{16}$ & 463 & 2.2 & 5.3 & 419 & 417 \\
\hline & & & & & & $v_{17}$ & 340 & 6.4 & 4.7 & 289 & 212 \\
\hline$v_{13}$ & 287 & 0 & 1.7 & 290 & 211 & $v_{18}$ & 226 & 0.036 & 0.28 & 172 & 193 \\
\hline$v_{14}$ & 162 & 13 & 1.0 & 153 & 71 & $v_{19}$ & 124 & 12 & 0.27 & 92 & 57 \\
\hline$v_{15}$ & 61 & 0 & 1.8 & 60 & 41 & $v_{20}$ & 47 & 0.0010 & 0.072 & 43 & 39 \\
\hline
\end{tabular}

${ }^{a}$ Reversed order; $v_{9}$ corresponds to the H-C vibration.

Vibrational frequencies computed for the selected electronic states (of interest to the analysis of IR spectra or of vibronic features) are collected in Table 2. The only available IR absorption spectrum of $\mathrm{CH}_{3} \mathrm{C}_{7} \mathrm{~N}$ was measured over 60 years ago by Bohlmann and Mannhardt ${ }^{31}$ for a $\mathrm{CCl}_{4}$ solution; digitization of the published figure points to band maxima at approximately 2290, 2240, 2210 , and $2190 \mathrm{~cm}^{-1}$. Our DFT results predict two very intense IR transitions, $v_{3}$ and $v_{4}$, at, 
respectively $2208 \mathrm{~cm}^{-1}$ and $2187 \mathrm{~cm}^{-1}$, i.e. matching the two of those observed. Other bands are expected to be much weaker. The 2240 and $2290 \mathrm{~cm}^{-1}$ bands observed in $\mathrm{CCl}_{4}$ could correspond to the $v_{2}$ band, possibly split by an anharmonic interaction (such interactions, involving triplebond stretching modes, were recognized ${ }^{28}$ for $\mathrm{CH}_{3} \mathrm{C}_{5} \mathrm{~N}$ ). In our study ${ }^{37}$ of the photochemically generated non-methylated analogue, $\mathrm{HC}_{7} \mathrm{~N}$, the IR absorption spectroscopy of solid Ar-isolated substance revealed traces of $v_{3}\left(2202.0 \mathrm{~cm}^{-1}\right)$ and $v_{1}\left(3323.1 \mathrm{~cm}^{-1}\right)$ bands, close to the theoretically predicted values. However, in the present experiments, aimed at $\mathrm{CH}_{3} \mathrm{C}_{7} \mathrm{~N}$, no IR absorption of this compound could be detected, and the identification was based solely on the analysis of electronic luminescence, just as in our recent study on UV-assisted synthesis of $\mathrm{HC}_{9} \mathrm{~N}$ from smaller chain precursor molecules.

\section{B. Dispersed phosphorescence}

In line with our previous studies, the aim here was to detect $\mathrm{CH}_{3} \mathrm{C}_{7} \mathrm{~N}$ by means of its phosphorescence, predicted to appear (Table 1) in the vicinity of the $\alpha \rightarrow X$ bands of $\mathrm{HC}_{7} \mathrm{~N}$. However, the use of $\mathrm{HC}_{5} \mathrm{~N}$ as one of the precursors implied the observation of its own intense phosphorescence, partly coinciding with anticipated $\mathrm{CH}_{3} \mathrm{C}_{7} \mathrm{~N} / \mathrm{HC}_{7} \mathrm{~N}$ emissions. Consequently, all detected $\mathrm{HC}_{5} \mathrm{~N}$ bands had to be thoroughly assigned. A listing of these, appending our former report, ${ }^{55}$ is available as the Supporting Information, Table S3 and Figures S2 and S3.

Luminescence from photoproducts generated in a $\mathrm{Kr} / \mathrm{CH}_{3} \mathrm{C}_{2} \mathrm{H} / \mathrm{HC}_{5} \mathrm{~N}$ matrix was detected especially in spectral windows around $19700 \mathrm{~cm}^{-1}(508 \mathrm{~nm}, 2.44 \mathrm{eV}$; see Figure 2) and 17500 $\mathrm{cm}^{-1}(571 \mathrm{~nm}, 2.17 \mathrm{eV})$, corresponding to the most intense phosphorescence bands of $\mathrm{HC}_{7} \mathrm{~N}^{37}$ An emission/excitation graph (for the first of the above-mentioned spectral ranges) is shown in 
Figure 2a. Two closely spaced emission bands are clearly discerned there; their individual excitation patterns indicate the presence of two disparate products. Another strong doublet, with components similarly spaced by $\sim 60 \mathrm{~cm}^{-1}$, appeared in the $17500 \mathrm{~cm}^{-1}$ region. The stronger component shown in Figure $2 \mathrm{~b}$ corresponds to a lower wavenumber, and is coincident with an already known ${ }^{37,57} \mathrm{HC}_{7} \mathrm{~N}$ emission band. It further gains intensity when excited at $46430 \mathrm{~cm}^{-1}$ (215.4 nm, $5.76 \mathrm{eV}$; see Figure 2a), in agreement with an excitation maximum previously observed for $\mathrm{HC}_{7} \mathrm{~N}$. The other band, with a different excitation spectrum (maximal signal observed upon excitation at $\left.43150 \mathrm{~cm}^{-1}, 231.7 \mathrm{~nm}, 5.35 \mathrm{eV}\right)$, can be assigned to $\mathrm{CH}_{3} \mathrm{C}_{7} \mathrm{~N}$. Indeed, theory predicted (Table 1) for $\mathrm{HC}_{7} \mathrm{~N}$ almost identical phosphorescence origin energy as for its methylated analogue. It should be noted that the applied computational method is not precise enough to rely on the exact magnitude of the difference between these two values.

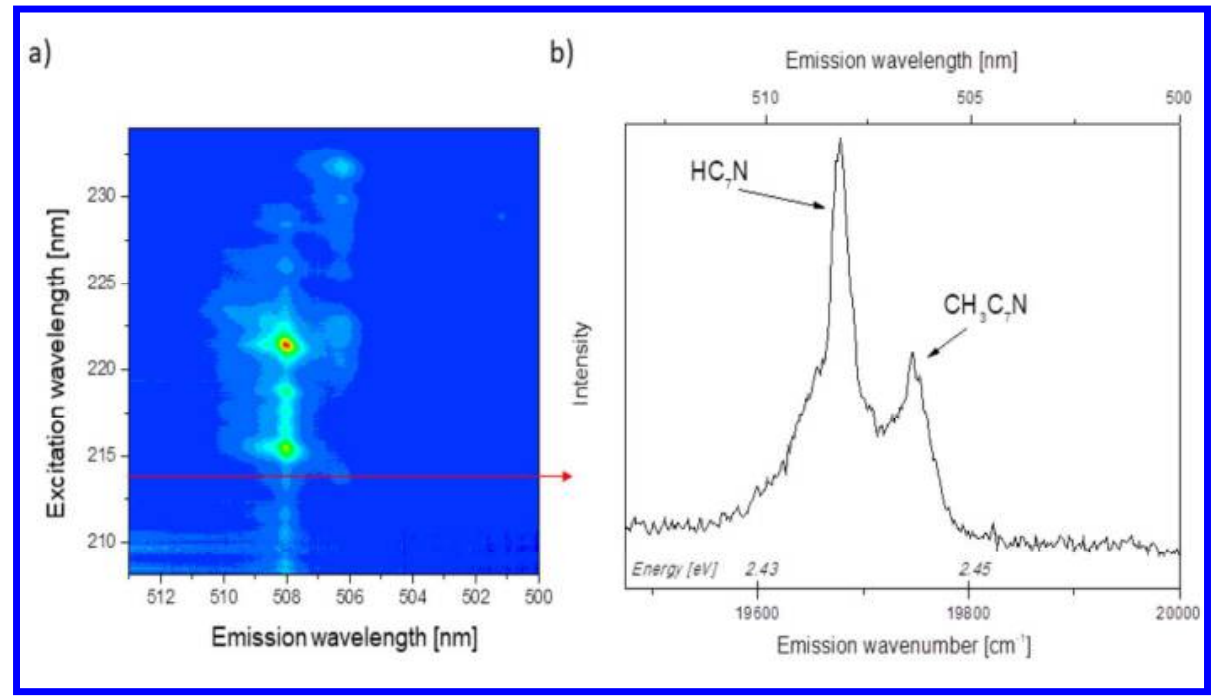

Figure 2. The excitation-emission map of a photolyzed $(193 \mathrm{~nm}) \mathrm{Kr} / \mathrm{CH}_{3} \mathrm{C}_{2} \mathrm{H} / \mathrm{HC}_{5} \mathrm{~N}(1000 / 1 / 1)$ matrix showing the spectral features of $\mathrm{HC}_{7} \mathrm{~N}$ and $\mathrm{CH}_{3} \mathrm{C}_{7} \mathrm{~N}$ phosphorescence (a). Red color represents the highest and deep blue the lowest phosphorescence intensity. Spectrum (b) corresponds to cross-sectioning the map along the red line, i.e. to phosphorescence excited at 213.5 $\mathrm{nm}\left(46840 \mathrm{~cm}^{-1}\right)$. 
The upper trace of Figure 3 presents $\mathrm{HC}_{7} \mathrm{~N}$ phosphorescence for a photolyzed $\mathrm{Kr} / \mathrm{CH}_{3} \mathrm{C}_{2} \mathrm{H} / \mathrm{HC}_{5} \mathrm{~N}$ matrix, excited at a maximum of UV absorption (215.4 $\mathrm{nm}$, Figure 2). The respective wavenumbers of vibronic bands are listed in Table 3, together with the values measured in previous $\mathrm{Ar} / \mathrm{HC}_{5} \mathrm{~N} / \mathrm{C}_{2} \mathrm{H}_{2}{ }^{37}$ and $\mathrm{Kr} / \mathrm{HC}_{5} \mathrm{~N} / \mathrm{C}_{2} \mathrm{H}_{2}{ }^{57}$ experiments; an additional, fairly weak band, identified as $3_{3}^{0}$, has been presently detected.

Table 3. $\mathrm{HC}_{7} \mathrm{~N}$ phosphorescence $\left(\alpha^{3} \Sigma^{+} \rightarrow X^{1} \Sigma^{+}\right)$bands, as measured in cryogenic matrices. Wavenumber $(w)$ values in $\mathrm{cm}^{-1}$. Relative wavenumbers $(\Delta *)$ calculated with respect to the preceding element of the vibronic progression.

\begin{tabular}{|c|c|c|c|c|c|c|}
\hline \multicolumn{2}{|c|}{ Ar (Ref. 37) } & \multicolumn{2}{|c|}{ Kr (Ref. 57) } & \multicolumn{3}{|c|}{$\mathrm{Kr}$ (this work) } \\
\hline 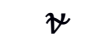 & $\Delta \psi$ & 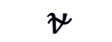 & $\Delta \psi$ & $\psi$ & $\Delta \psi$ & Assignment \\
\hline 19764 & - & 19700 & - & 19690 & - & $0_{0}^{0}$ \\
\hline 17565 & 2199 & 17500 & 2200 & 17490 & 2200 & $3_{1}^{0}$ \\
\hline 15378 & 2187 & 15310 & 2190 & 15310 & 2180 & $3_{2}^{0}$ \\
\hline & & & & $13140^{a}$ & $2170^{a}$ & $33_{3}^{0}$ \\
\hline
\end{tabular}

${ }^{a} \pm 20 \mathrm{~cm}^{-1}$; the band is weak and broad.

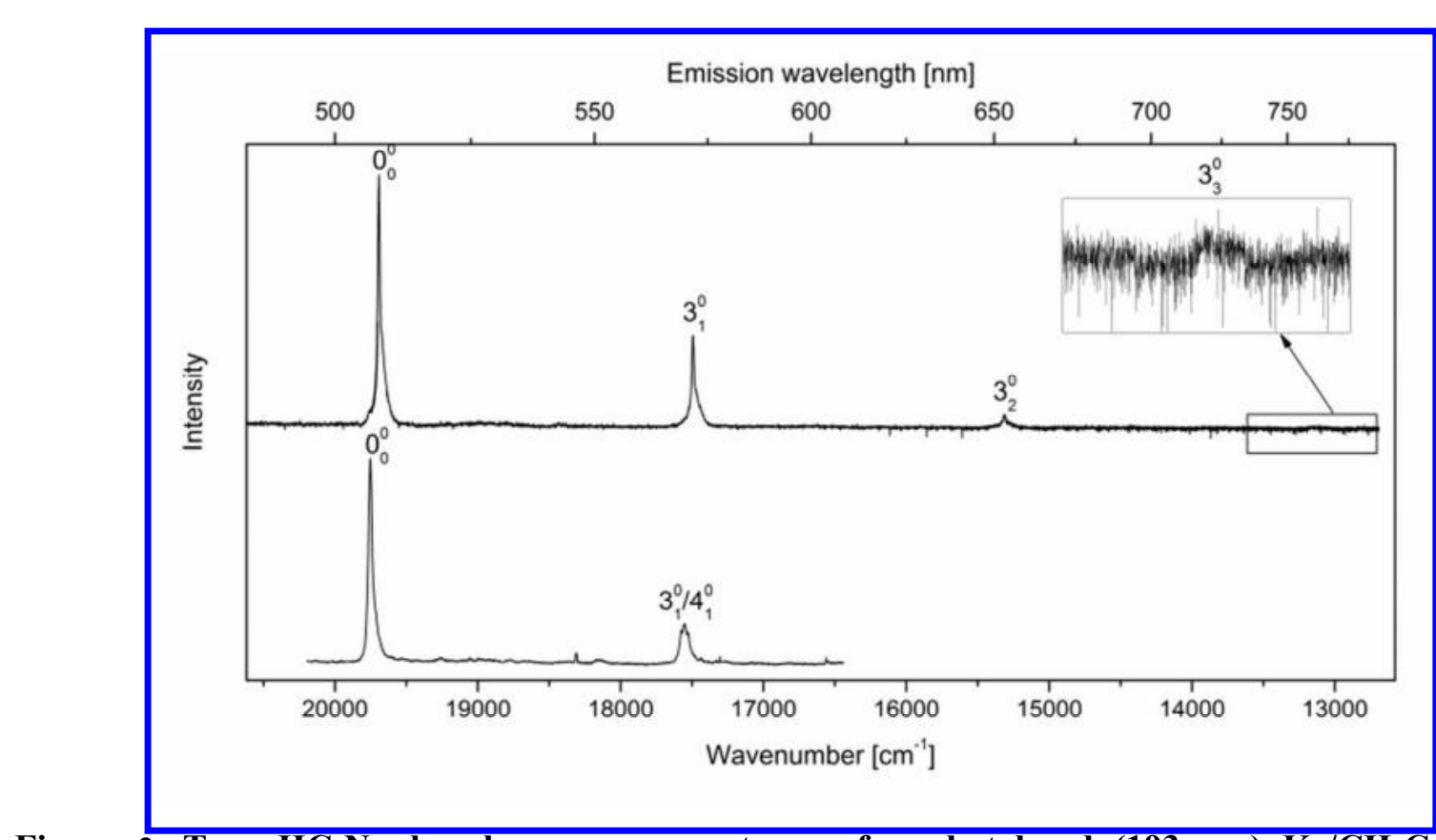

Figure 3. Top: $\mathrm{HC}_{7} \mathrm{~N}$ phosphorescence spectrum of a photolysed $(193 \mathrm{~nm}) \mathrm{Kr} / \mathrm{CH}_{3} \mathrm{C}_{2} \mathrm{H} / \mathrm{HC}_{5} \mathrm{~N}$ $(1000 / 2 / 1)$ matrix excited at $46430 \mathrm{~cm}^{-1}(5.76 \mathrm{eV}, 215.4 \mathrm{~nm})$. Bottom: $\mathrm{CH}_{3} \mathrm{C}_{7} \mathrm{~N}$ phosphorescence of a photolyzed (193 nm) $\mathrm{Kr} / \mathrm{CH}_{3} \mathrm{C}_{2} \mathrm{H} / \mathrm{HC}_{5} \mathrm{~N}(1000 / 2 / 1)$ matrix excited at $43150 \mathrm{~cm}^{-1}(5.35 \mathrm{eV}, 231.7 \mathrm{~nm})$. 
Just as indicated by Figure 2a, the excitation at $231.7 \mathrm{~nm}$ led preferably to the phosphorescence of $\mathrm{CH}_{3} \mathrm{C}_{7} \mathrm{~N}$ (lower curve of Figure 3), with prominent $19750 \mathrm{~cm}^{-1}$ and $17550 \mathrm{~cm}^{-1}$ bands, very similar to that of $\mathrm{HC}_{7} \mathrm{~N}$. Of note, the observed $\mathrm{CH}_{3} \mathrm{C}_{7} \mathrm{~N}$ phosphorescence was less intense than that of $\mathrm{HC}_{7} \mathrm{~N}$, preventing the detection of lower frequency features. The position (corresponding to $2.45 \mathrm{eV}$ ) of the most intense of the said bands matches reasonably well (the same quality of agreement as for $\left.\mathrm{HC}_{7} \mathrm{~N}\right)$ with what is expected $(2.23 \mathrm{eV}$, Table 1) for the vibrationless origin of the $a^{3} \mathrm{~A}^{\prime} \rightarrow X^{1} \mathrm{~A}_{1}$ system. The bands are $2200 \mathrm{~cm}^{-1}$ apart, in acceptable agreement with the present predictions (see Table 2) for either $v_{4}$ or $v_{3} X$-state frequencies. Using the $\mathrm{HC}_{7} \mathrm{~N}$ case as a guide, preference could possibly be given to the pseudosymmetric mode $v_{4}\left(2187 \mathrm{~cm}^{-1}\right.$; see Table S2 in Supporting Information for the visualization). Similar reasoning was used ${ }^{29}$ in the analysis of the $\mathrm{CH}_{3} \mathrm{C}_{5} \mathrm{~N}$ spectrum, based on its resemblance to that of $\mathrm{HC}_{5} \mathrm{~N}$. However, constancy of $\mathrm{HC}_{7} \mathrm{~N} / \mathrm{CH}_{3} \mathrm{C}_{7} \mathrm{~N}$ "splitting" observed in the consecutive elements of the vibronic progression suggests that the vibrational quantum governing the progression of $\mathrm{CH}_{3} \mathrm{C}_{7} \mathrm{~N}$ is very close to 2200 $\mathrm{cm}^{-1}$, i.e. to the value found for the analogous progression of $\mathrm{HC}_{7} \mathrm{~N}$. This points to the mode $v_{3}$ $\left(2208 \mathrm{~cm}^{-1}\right)$ rather than $v_{4}$. Additionally, $v_{3}$ shows the highest Raman activity, and the stretchings of such a character have already been shown to shape the main vibronic progressions of cyanopolyacetylenic molecules. ${ }^{40,57,58}$ Broadness of the $17550 \mathrm{~cm}^{-1}$ band may in fact suggest the presence of overlapping $v_{3}$ and $v_{4}$ progressions (the Raman activity of $v_{4}$ is also high). 


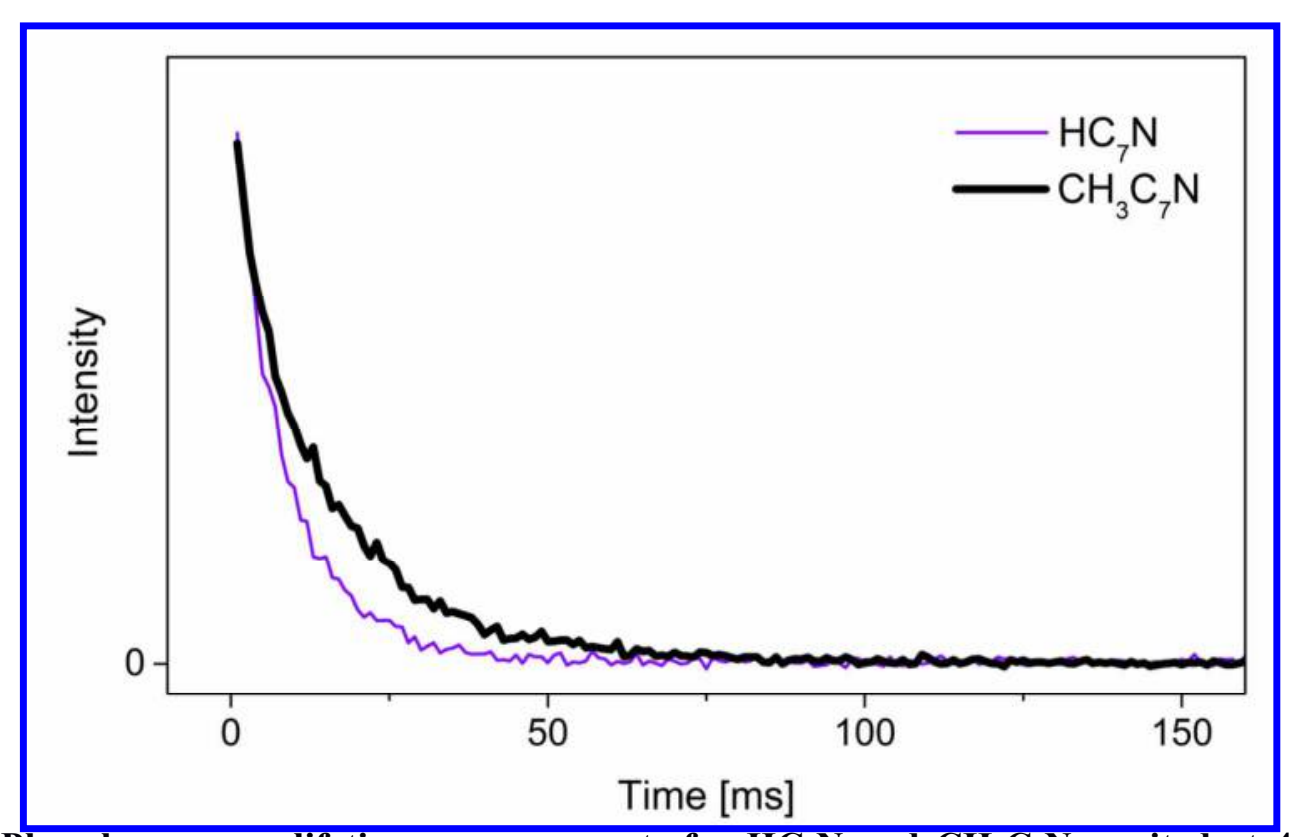

Figure 4. Phosphorescence lifetime measurements for $\mathrm{HC}_{7} \mathrm{~N}$ and $\mathrm{CH}_{3} \mathrm{C}_{7} \mathrm{~N}$, excited at $46430 \mathrm{~cm}^{-1}$ (215.4) $\mathrm{nm}$ and $43150 \mathrm{~cm}^{-1}(231.7 \mathrm{~nm})$, respectively.

$\mathrm{HC}_{7} \mathrm{~N}$ and $\mathrm{CH}_{3} \mathrm{C}_{7} \mathrm{~N}$ emission decays were registered, as demonstrated in Figure 4. The band assigned to the origin of $\mathrm{HC}_{7} \mathrm{~N}$ phosphorescence showed a mono-exponential decay with $\tau=(8 \pm 0.5) \mathrm{ms}$. This Kr-matrix value is by far smaller than $\tau=(34 \pm 1.5) \mathrm{ms} \mathrm{reported}^{37}$ for solid Ar. The band marking the origin of $\mathrm{CH}_{3} \mathrm{C}_{7} \mathrm{~N}$ emission was decaying with $\tau=(15 \pm 1) \mathrm{ms}$.

Table 4. Phosphorescence lifetime (ms) for solid Kr-isolated cyanopolyacetylenes and methylcyanopolyacetylenes.

\begin{tabular}{|c|c|c|c|}
\hline $\mathrm{HC}_{n} \mathrm{~N}$ & $\tau$ & $\mathrm{CH}_{3} \mathrm{C}_{n} \mathrm{~N}$ & $\tau$ \\
\hline & & & \\
\hline $\mathrm{HC}_{5} \mathrm{~N}^{a}$ & 40 & $\mathrm{CH}_{3} \mathrm{C}_{5} \mathrm{~N}^{b}$ & 150 \\
\hline $\mathrm{HC}_{7} \mathrm{~N}$ & 8 & $\mathrm{CH}_{3} \mathrm{C}_{7} \mathrm{~N}$ & 15 \\
\hline $\mathrm{HC}_{9} \mathrm{~N}^{c}$ & 3.9 & & \\
\hline
\end{tabular}

${ }^{a}$ After Ref. 57. ${ }^{b}$ After Ref. 29. ${ }^{c}$ After Ref. 39.

These data, together with those reported for other $\mathrm{H}(\mathrm{C} \equiv \mathrm{C})_{n} \mathrm{CN}$ and $\mathrm{CH}_{3}(\mathrm{C} \equiv \mathrm{C})_{n} \mathrm{CN}$ molecules isolated in solid $\mathrm{Kr}$, are collected in Table 4. Within each of these series, there is a pronounced decrease of lifetime as the length of a polyacetylenic backbone increases. Such a regularity most 
likely originates in the diminishing singlet-triplet gap and in the increasing number of chaindeforming vibrational modes; both factors may enhance non-radiative relaxation channels. Hcapped cyanopolyacetylenes are characterized by shorter phosphorescence lifetimes than their methylated derivatives. It remains an open question whether this effect is of an intramolecular or of an environmental nature. One may speculate that matrix trapping sites occupied by $C_{\infty \mathrm{v}}$ molecules are tighter than those available to their $C_{3 \mathrm{v}}$ analogues (less $\mathrm{Kr}$ atoms need to be removed from an fcc lattice to accommodate an $\mathrm{H}$-capped than a $\mathrm{CH}_{3}$-capped molecule), and hence the interaction of $C_{\infty \mathrm{v}}$ species with lattice phonons is stronger, promoting the non-radiative electronic relaxation.

C. Singlet excited electronic states

Resemblance of the chromophores of $\mathrm{HC}_{7} \mathrm{~N}$ and $\mathrm{CH}_{3} \mathrm{C}_{7} \mathrm{~N}$ is illustrated by the predicted geometries (Figure 1). It is also reflected in the corresponding DFT-derived electronic transition energies (Table 1), characterized by similarities already seen within the pairs of methyl- and hydrogen-capped cyanopolyacetylenes $\mathrm{CH}_{3} \mathrm{C}_{3} \mathrm{~N} / \mathrm{HC}_{3} \mathrm{~N}^{22,24,54}$ or $\mathrm{CH}_{3} \mathrm{C}_{5} \mathrm{~N} / \mathrm{HC}_{5} \mathrm{~N}^{29}$. Singlet-singlet electronic absorption features of $\mathrm{CH}_{3} \mathrm{C}_{7} \mathrm{~N}$ and $\mathrm{HC}_{7} \mathrm{~N}$ (accessed here by means of phosphorescence excitation) were therefore expected to partially overlap. 


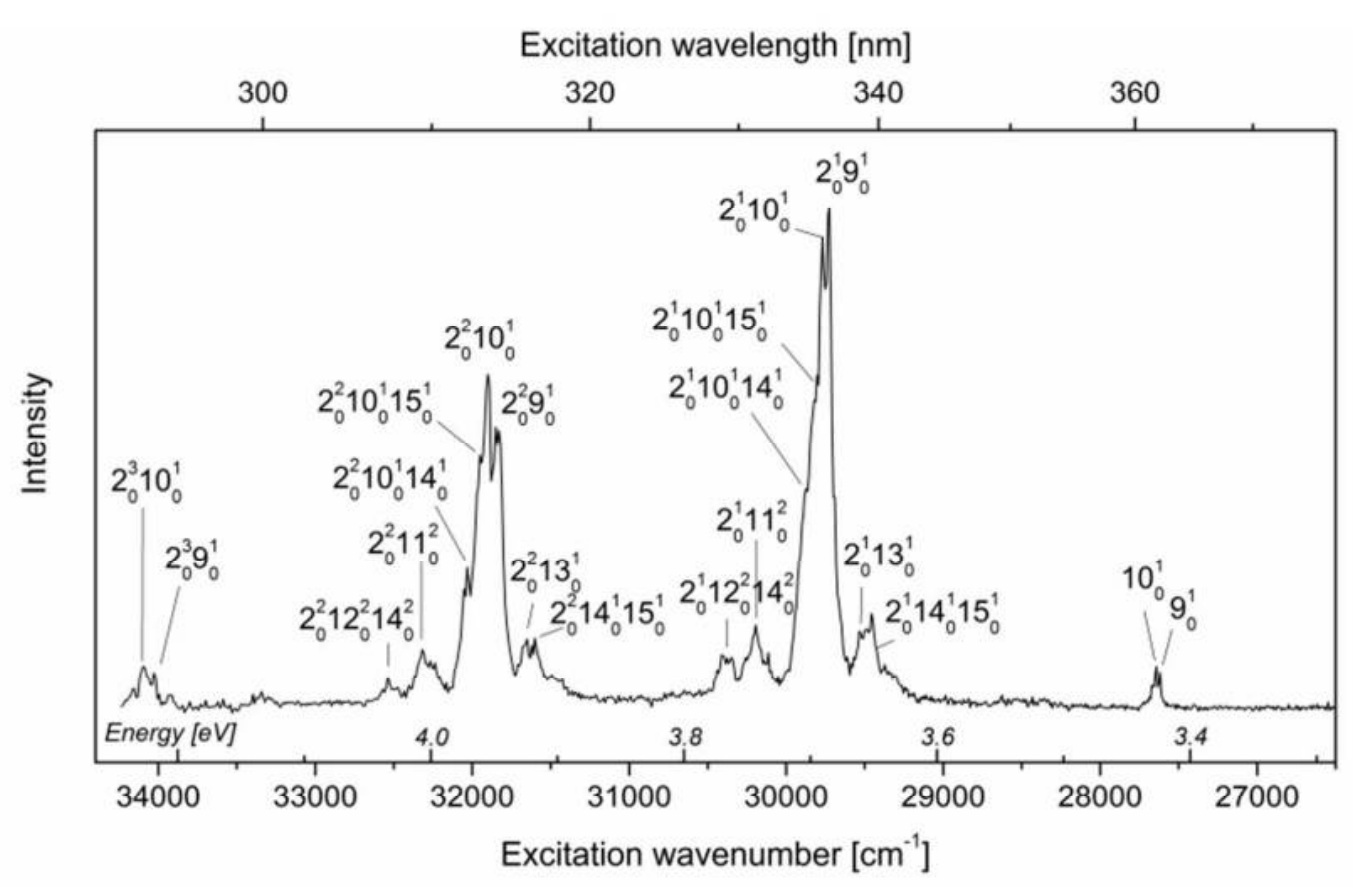

Figure $5 . B-X^{2}$ system of $\mathrm{HC}_{7} \mathrm{~N}$, as revealed by the phosphorescence excitation spectrum (detection at the $3_{0}^{1}$ band; $\left.17500 \mathrm{~cm}^{-1}\right)$ of a photolyzed $(193 \mathrm{~nm}) \mathrm{Kr} / \mathrm{C}_{4} \mathrm{H}_{2} / \mathrm{HC}_{5} \mathrm{~N}(1000 / 1 / 1)$ matrix. Wavelength-dependent laser intensity variations might distort the phosphorescence intensity pattern. Wavenumbers of tentatively identified bands are listed in Table 5.

A part of the $\mathbb{B}^{1} \Delta-X^{1} \Sigma^{+}$system of $\mathrm{HC}_{7} \mathrm{~N}$ is presented in Figure 5 . As mentioned in the Theoretical predictions subsection, the corresponding "0-0" feature (system origin) cannot show up in UV absorption or luminescence excitation spectra. In spite of that, $B^{1} \Delta-X^{1} \Sigma^{+}$transitions can occur by the coupling to $\pi$-symmetry vibrations (Herzberg-Teller effect). For the analogous electronic systems of $\mathrm{HC}_{3} \mathrm{~N}^{54}$ and $\mathrm{HC}_{5} \mathrm{~N},{ }^{55}$ this was shown to happen via the promoting zig-zag modes, pointing to a similar function, in $\mathrm{HC}_{7} \mathrm{~N}$, of the vibration $v_{10}$ (predicted $B$-state wavenumber of $553 \mathrm{~cm}^{-1}$ ). This role of $v_{10}$ was also indicated by transition dipole moment calculations (see Theoretical predictions). However, the main bands of the most prominent vibronic progression, spaced by $\sim 2100 \mathrm{~cm}^{-1}$, are clearly doubled, suggesting the involvement of 
yet another promoting $\pi$-symmetry mode, tentatively identified here as $v_{9}(B$-state wavenumber prediction: $522 \mathrm{~cm}^{-1}$ ). Given that the lowest-wavenumber doublet was detected at $27620 / 27640$ $\mathrm{cm}^{-1}$, the $B-X$ origin is expected around 27100 or $27120 \mathrm{~cm}^{-1}$, i.e. $3.36 \mathrm{eV}$. Further profiting from analogies with shorter $\mathrm{H}(\mathrm{C} \equiv \mathrm{C})_{n} \mathrm{CN}$ species (which, compared to $\mathrm{HC}_{7} \mathrm{~N}$, feature similar molecular distortions upon $B-\not X$ excitation, similar patterns of the excited electronic states distribution, and show similarities in phosphorescence spectra), the spacing of the main vibronic progression can be attributed to the $\mathbb{B}$-state mode $v_{2}$ (predicted wavenumber $2117 \mathrm{~cm}^{-1}$ ), analogous to the $v_{3}$ stretching of $X$ (see Table S1). Wavenumbers of $\mathrm{HC}_{7} \mathrm{~N}$ bands identified in Figure 5 are listed in Table 5.

The analogous, low energy region of the $\mathrm{CH}_{3} \mathrm{C}_{7} \mathrm{~N}$ phosphorescence excitation spectrum showed just two weak bands attributable to the $B^{1} \mathrm{E}-\not{ }^{1} \mathrm{~A}_{1}$ system, at $29330 \mathrm{~cm}^{-1}(3.64 \mathrm{eV})$ and 31400 $\mathrm{cm}^{-1}$ (i.e. spaced by the value of $2070 \mathrm{~cm}^{-1}$, characteristic of triple bond stretching frequencies). The known spectra of smaller (i.e. $n=1$ or 2$) \mathrm{H}(\mathrm{C} \equiv \mathrm{C})_{n} \mathrm{CN}$ and $\mathrm{CH}_{3}(\mathrm{C} \equiv \mathrm{C})_{n} \mathrm{CN}$ molecules indicate that the forbiddance of $B-X$ transitions (and hence the lack of vibrationless origin bands), strictly valid for $\mathrm{H}(\mathrm{C} \equiv \mathrm{C})_{n} \mathrm{CN}$ species, is in practice effective also for the methyl-capped derivatives. It should be recalled that theory predicts a shift of approx. $500 \mathrm{~cm}^{-1}$ (see Table 1) between the $B-X$ origins of $\mathrm{HC}_{7} \mathrm{~N}$ and $\mathrm{CH}_{3} \mathrm{C}_{7} \mathrm{~N}$. A very similar value of $475 \mathrm{~cm}^{-1}$ was experimentally found for this shift in the analogous case of the $\mathrm{HC}_{5} \mathrm{~N}, \mathrm{CH}_{3} \mathrm{C}_{5} \mathrm{~N}$ pair of molecules. ${ }^{29,55}$ Therefore, the $29330 \mathrm{~cm}^{-1}$ and $31400 \mathrm{~cm}^{-1}$ features can be related to the $\mathrm{HC}_{7} \mathrm{~N}$ doublets around 29750 and $31860 \mathrm{~cm}^{-1}$, respectively. The detected bands are presumably due to the coupling of $B-X$ with a 'zig-zag' distortion of the carbon-nitrogen chain, combined with a chain stretching mode. This suggests the placement of $B{ }^{1} \mathrm{E}-X^{1} \mathrm{~A}_{1}$ origin at approx. $3.32 \mathrm{eV}$, an estimation coming from the appropriate lowering of the above-mentioned value $29330 \mathrm{~cm}^{-1}$, by 
subtracting from it the frequencies of (i) the stretching that governs the main vibronic progression (measured value: $2070 \mathrm{~cm}^{-1}$ ) and (ii) the vibronic-coupling mode (most likely the $v_{14}$ zig-zag chain-bending; predicted value: $523 \mathrm{~cm}^{-1}$ ).

Table 5. Wavenumbers $\left(\mathrm{cm}^{-1}\right)$ of $B^{1} \Delta-X^{1} \Sigma^{+}$bands tentatively identified in the phosphorescence excitation spectrum of $\mathrm{HC}_{7} \mathrm{~N}$ in solid krypton.

\begin{tabular}{|c|c|}
\hline \multirow{2}{*}{27620} & Assignment \\
\hline 27640 & $9_{0}^{1}$ \\
\hline 29460 & $10_{0}^{1}$ \\
\hline 29520 & $2_{0}^{1} 14_{0}^{1} 15_{0}^{1}$ \\
\hline 29730 & $2_{0}^{1} 13_{0}^{1}$ \\
\hline 29770 & $2_{0}^{1} 10_{0}^{1}$ \\
\hline 30190 & $2_{0}^{1} 11_{0}^{2}$ \\
\hline 30390 & $2_{0}^{1} 12_{0}^{2} 14_{0}^{2}$ \\
\hline 31600 & $2_{0}^{2} 14_{0}^{2} 15_{0}^{2}$ \\
\hline 31670 & $2_{0}^{2} 13_{0}^{1}$ \\
\hline 31840 & $2_{0}^{2} 9_{0}^{1}$ \\
\hline 31900 & $2_{0}^{2} 10_{0}^{1}$ \\
\hline 31950 & Site / \\
& $2_{0}^{2} 10_{0}^{1} 15_{0}^{1}$ \\
\hline 32030 & Site / \\
& $2_{0}^{2} 10_{0}^{1} 14_{0}^{1}$ \\
\hline 32320 & $2_{0}^{2} 11_{0}^{2}$ \\
\hline 32540 & $2_{0}^{2} 12_{0}^{2} 14_{0}^{2}$ \\
\hline 34030 & $2_{0}^{3} 9_{0}^{1}$ \\
\hline 34090 & $2_{0}^{3} 10_{0}^{1}$ \\
\hline
\end{tabular}

Figure 6 presents the dependence of experimentally found $B-\not$ origin wavelength on the molecule chain length, for two homologues series: $\mathrm{H}(\mathrm{C} \equiv \mathrm{C})_{n} \mathrm{CN}$ and $\mathrm{CH}_{3}(\mathrm{C} \equiv \mathrm{C})_{n} \mathrm{CN}$. Also shown, for comparison, are the corresponding theoretical predictions, separately for vertical and vibrationless transitions. All sets of data follow linear patterns and, for a given $n$ value, the wavelengths found for $\mathrm{H}(\mathrm{C} \equiv \mathrm{C})_{n} \mathrm{CN}$ and $\mathrm{CH}_{3}(\mathrm{C} \equiv \mathrm{C})_{n} \mathrm{CN}$ are very close to one another. Moreover, 
experimental values are consistently lower than the theoretically derived ones, with a fortuitous agreement between the wavelengths of experimental vibrationless transitions and of theoretical vertical transitions (as already reported for $\mathrm{H}(\mathrm{C} \equiv \mathrm{C})_{n} \mathrm{CN}$ molecules). ${ }^{39}$

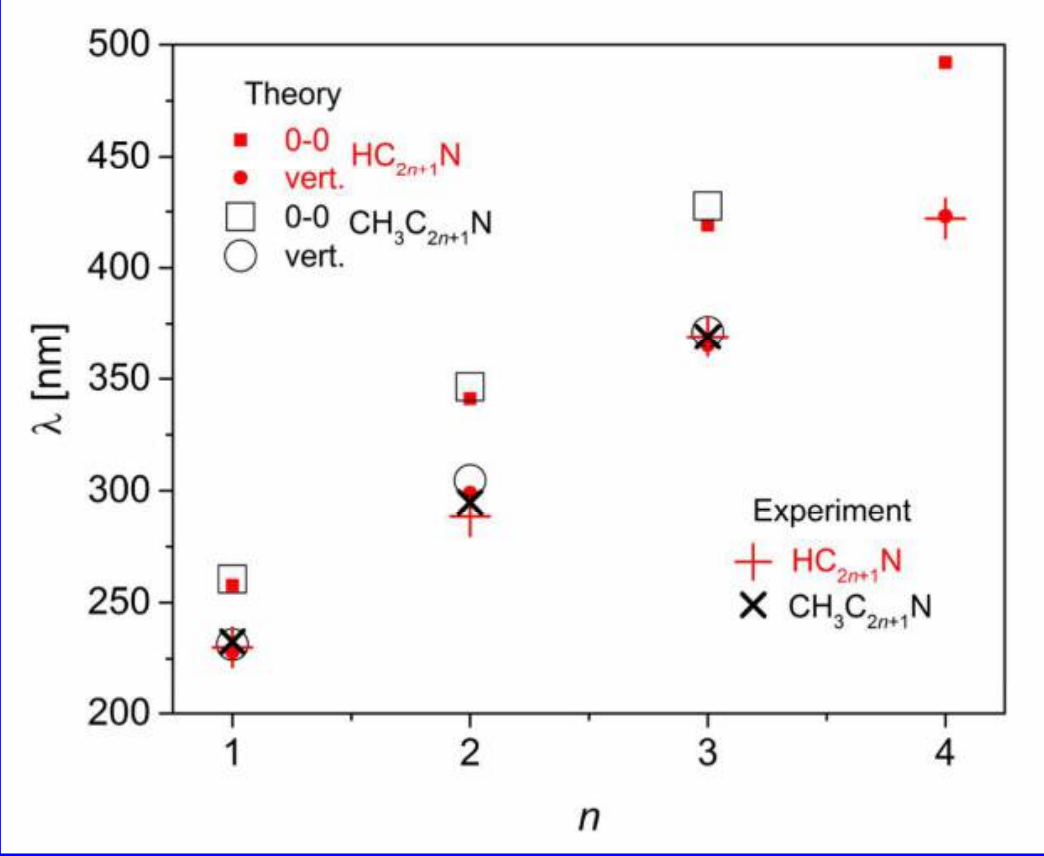

Figure 6. Dependence of $B-X$ transition wavelength $(\lambda)$ on the carbon chain length $(n)$, for $\mathrm{HC}_{2 n+1} \mathrm{~N}$ and $\mathrm{CH}_{3} \mathrm{C}_{2 n+1} \mathrm{~N}$. Theoretical values are those of this work and Refs. 28, 38. Experimental data correspond to $B-X$ origin wavelengths in solid $\mathrm{Kr}$ (this work and Refs. 29, 55), with the exception of $n=1$ : for $\mathrm{HC}_{3} \mathrm{~N}$ the value found in solid $\mathrm{Ar}^{59}$ is given (Ar-to-Kr shift being negligible in the scale of the plot), and the $\mathrm{CH}_{3} \mathrm{C}_{3} \mathrm{~N}$ entry corresponds to the corrected gas-phase value ${ }^{24}$ gas-to-Kr shift is estimated as $-500 \mathrm{~cm}^{-1}$.

The high-energy region of phosphorescence excitation spectra, above $43000 \mathrm{~cm}^{-1}$, gave access to fully allowed $\mathbb{E}-X$ transitions of $\mathrm{HC}_{7} \mathrm{~N}$ and $\mathrm{CH}_{3} \mathrm{C}_{7} \mathrm{~N}$. Just as predicted (Table 1), the two $\mathbb{E}-X^{x}$ systems are located very close to one another. 


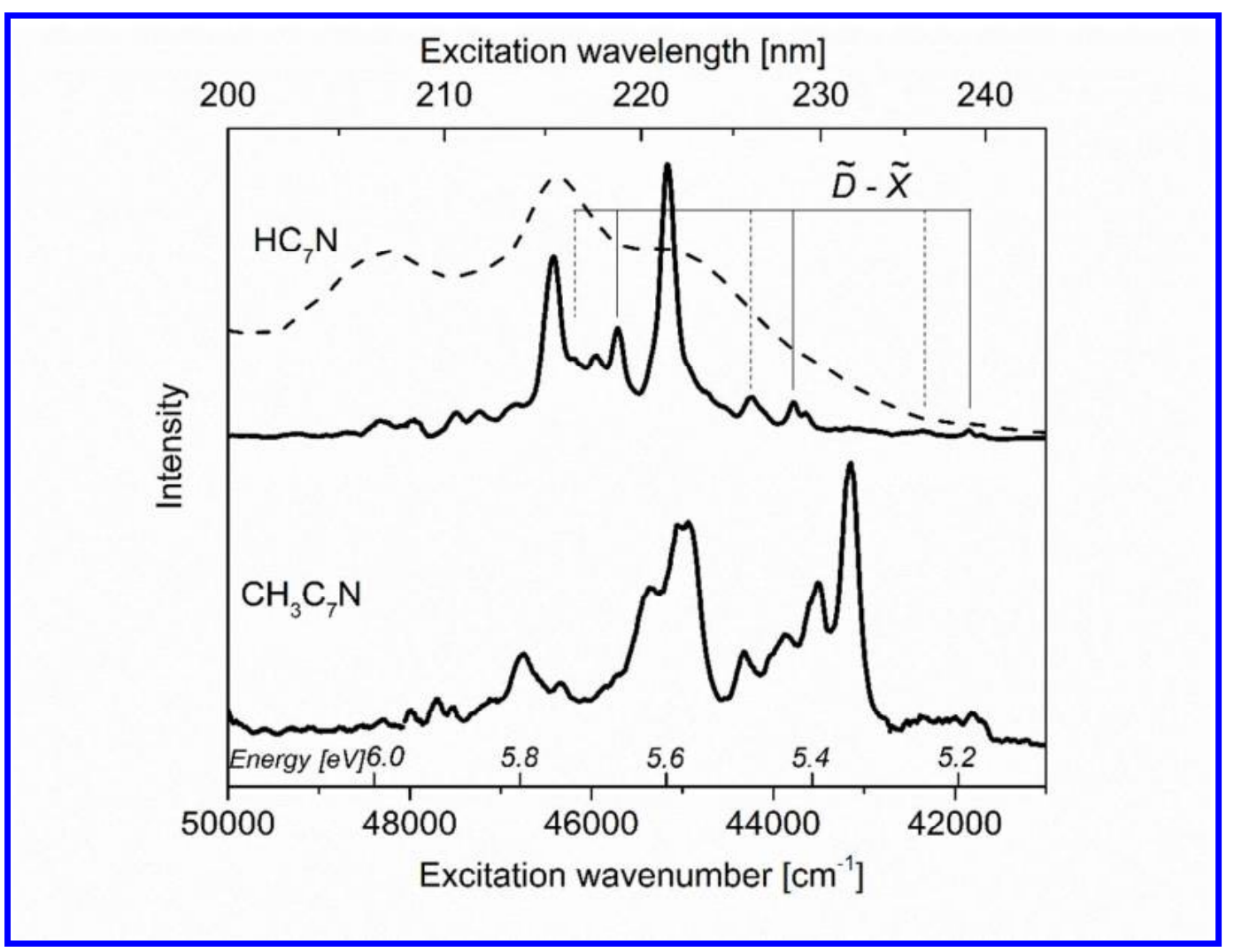

Figure 7. Top: $E-X$ transitions in the excitation spectrum of $\mathrm{HC}_{7} \mathrm{~N}$ phosphorescence (detection at the 0-0 band, $\left.19690 \mathrm{~cm}^{-1}\right)$ emitted from a photolyzed $(193 \mathrm{~nm}) \mathrm{Kr} / \mathrm{CH}_{3} \mathrm{C}_{2} \mathrm{H} / \mathrm{HC}_{5} \mathrm{~N}(1000 / 1 / 1)$ matrix. Dashed trace (reproduced from Ref. 43) corresponds to the absorption spectrum of $\mathrm{HC}_{7} \mathrm{~N}$ in acetonitrile. Tentatively identified elements of the $\theta-X$ vibronic progression are indicated. Bottom: Phosphorescence excitation spectrum (detection at the 0-0 band, $19750 \mathrm{~cm}^{-1}$ ) assigned to the $\overparen{E}-X$ electronic system of $\mathrm{CH}_{3} \mathrm{C}_{7} \mathrm{~N}$, coming from a $\mathrm{Kr} / \mathrm{CH}_{3} \mathrm{C}_{2} \mathrm{H} / \mathrm{HC}_{5} \mathrm{~N}(1000 / 2 / 1)$ matrix irradiated at $193 \mathrm{~nm}$. Wavelength-dependent laser intensity variations might distort the phosphorescence intensity patterns.

Figure 7 (bottom) presents the relevant system of bands identified as due to $\mathrm{CH}_{3} \mathrm{C}_{7} \mathrm{~N}$. A UV absorption feature reported by Bohlmann ${ }^{31}$ for an ether solution of $\mathrm{CH}_{3} \mathrm{C}_{7} \mathrm{~N}$ (centered at $44740 \mathrm{~cm}^{-1}$ ), remains in reasonable agreement with present data. The first strong band of the excitation spectrum is located at $43150 \mathrm{~cm}^{-1}(5.35 \mathrm{eV}$ or $231.7 \mathrm{~nm})$, very close to the predicted origin of $\mathbb{E}^{1} \mathrm{~A}_{1}-X^{1} \mathrm{~A}_{1}$ transitions (5.40 eV, see Table 1). Several other bands of this system are 
tentatively identified, as proposed in Table 6 . The second strong maximum, around $45000 \mathrm{~cm}^{-1}$, is broad and may correspond to more than one band. Therefore, the main vibronic spacing, given by a distance between the two major spectral features, is not well defined. Its value of $\sim 1800 \mathrm{~cm}^{-1}$ is smaller than the closest DFT prediction for $\mathbb{E}$ state modes listed in Table 2: $v_{5}$ of $1917 \mathrm{~cm}^{-1}$ or $v_{4}$ of $1969 \mathrm{~cm}^{-1}$. It should be noted that the excitation at $43150 \mathrm{~cm}^{-1}$, which leads to the strongest phosphorescence, was also found to potently destroy the molecule over time (an effect that was not significant for the H-capped analogue). This contributed to a relatively high intensity of detected $\mathrm{HC}_{7} \mathrm{~N}$ bands compared to those of $\mathrm{CH}_{3} \mathrm{C}_{7} \mathrm{~N}$.

Table 6. Vibronic band attributions proposed for the $E-X$ electronic system of $\mathrm{CH}_{3} \mathrm{C}_{7} \mathrm{~N}$. Wavenumbers $\left(\mathrm{cm}^{-1}\right)$ rounded to the nearest 10. Relative wavenumbers give the distance from the vibrationless $0_{0}^{0}$ band.

\begin{tabular}{|c|c|c|}
\hline$\ngtr$ & $\Delta \nsim$ & Tentative assignment \\
\hline 43150 & 0 & $0_{0}^{0}$ \\
\hline 43520 & 370 & $10_{0}^{1}$ \\
\hline $43880^{a}$ & 730 & $9_{0}^{1} / 10_{0}^{2}$ \\
\hline 44330 & 1180 & $9_{0}^{1} 10_{0}^{1}$ \\
\hline $45000^{b}$ & 1850 & $5_{0}^{1}$ \\
\hline 45370 & 2220 & $5_{0}^{1} 10_{0}^{1} / 2_{0}^{1}$ \\
\hline 46350 & 3200 & $5_{0}^{1} 6_{0}^{1} / 2_{0}^{1} 8_{0}^{1}$ \\
\hline 46770 & 3620 & $5_{0}^{2}$ \\
\hline
\end{tabular}

a This broad band is shifted by $\sim 2000 \mathrm{~cm}^{-1}$ from another broad feature at lower energy, assigned to $\theta-X^{2}$ (see text), it may therefore also belong to the $\theta-X^{2}$ system, rather than to $\mathbb{E}-\not$.

${ }^{b}$ Broad band, possibly comprising a $44940 / 45070 \mathrm{~cm}^{-1}$ doublet, tentatively due to $5_{0}^{1}$ coupled with $13_{0}^{2}$.

The top part of Figure 7 shows the analogous region of the phosphorescence excitation spectrum, as measured for $\mathrm{HC}_{7} \mathrm{~N}$ (qualitatively similar data, for the compound produced in electric discharges through a $\mathrm{HC}_{3} \mathrm{~N} / \mathrm{Kr}$ mixture, were reported by Turowski et al. ${ }^{40}$ ). The first intense 
band, at $45180 \mathrm{~cm}^{-1}(221.3 \mathrm{~nm})$, almost matches the theoretical prediction of $5.63 \mathrm{eV}$ (Table 1). As can be seen in Figure 7, a much less resolved $\mathrm{UV}$ absorption of $\mathrm{HC}_{7} \mathrm{~N}$ in acetonitrile, reported in Wakabayashi et al., ${ }^{43}$ appears in the same spectral region. The resemblance of $\mathrm{HC}_{7} \mathrm{~N}$ and $\mathrm{HC}_{9} \mathrm{~N}$ excitation spectra, reported by Szczepaniak et al., ${ }^{39}$ helps in the assignment of bands. More precisely, at the low energy side, the spectra of both of $\mathrm{HC}_{7} \mathrm{~N}$ and $\mathrm{HC}_{9} \mathrm{~N}$ show weak features, most likely due to the $\mathbb{D}-X^{2}$ system, with a vibronic spacing of $\sim 1930 \mathrm{~cm}^{-1}$ (a typical triple bond stretching frequency). The $45180 \mathrm{~cm}^{-1}$ band does not belong to the $\mathbb{D}-\not x$ progressions (marked in Figure 7) and is assigned here to the origin of the $\mathbb{E}-\not$ system. Table 7 lists tentative identifications of the most intense bands.

As previously mentioned, theoretical predictions pointed to the similarities between the first excited states of $\mathrm{HC}_{7} \mathrm{~N}$ and $\mathrm{CH}_{3} \mathrm{C}_{7} \mathrm{~N}$ (Table 1). However, as depicted by Figure 7, the measured patterns of $E-X$ bands differ for the two molecules, and the presence of $\mathbb{E}-\not$ transitions in the $\mathrm{CH}_{3} \mathrm{C}_{7} \mathrm{~N}$ spectrum is less obvious (even if possibly manifested with unresolved bands around $42000 \mathrm{~cm}^{-1}$ ). Long vibronic progressions are not expected in $\mathbb{E}-\not X$ spectra, considering that the respective electronic excitation is accompanied by little change in molecular geometry. Our tentative band assignments, provided in Tables 6 and 7, do not involve, for the two molecules, the same types of vibrational modes; it is mainly a $\mathrm{C}-\mathrm{C}$ stretching $\left(v_{6}\right)$ for $\mathrm{HC}_{7} \mathrm{~N}$ and a triple bond stretching $\left(v_{5}\right)$ for $\mathrm{CH}_{3} \mathrm{C}_{7} \mathrm{~N}$. No close equivalent to $v_{6}$ of $\mathrm{HC}_{7} \mathrm{~N}$ does in fact exist for $\mathrm{CH}_{3} \mathrm{C}_{7} \mathrm{~N}$ (see Tables S1 and S2 of the Supporting Information), what may explain the differences in band patterns observed for these spectra. Moreover, the vibronic pattern of $\mathrm{HC}_{7} \mathrm{~N}$ spectrum, more difficult to interpret than that found for $\mathrm{CH}_{3} \mathrm{C}_{7} \mathrm{~N}$, might result from the energetic proximity of the two allowed electronic systems: $\mathbb{E}-\not$ and $F-X$. In the case of $\mathrm{CH}_{3} \mathrm{C}_{7} \mathrm{~N}$, the separation of $\mathbb{E}$ 
and $H$ states (analogous to $\mathbb{E}$ and $\mathbb{F}$ of $\mathrm{HC}_{7} \mathrm{~N}$ ) is substantially larger, probably reducing their mutual interaction.

Table 7. Wavenumbers $\left(\mathrm{cm}^{-1}\right)$ of the most intense bands observed in the $\mathbb{E}-\not$ region of the $\mathrm{HC}_{7} \mathrm{~N}$ excitation spectrum. $\theta-X^{X}$ bands listed in italics. Relative wavenumbers give the distance from the vibrationless $\left(0_{0}^{0}\right)$ band of the $E-X^{x}$ system.

\begin{tabular}{|c|c|c|}
\hline$*$ & $\Delta *$ & Tentative assignment \\
\hline 41720 & & $\theta$ (minor band) \\
\hline 41860 & & $\theta$ (main band) \\
\hline 43660 & & $\bar{D}($ minor band $)+v($ triple bond stretch $)$ \\
\hline 43790 & & $D($ main band $)+v($ triple bond stretch $)$ \\
\hline 44250 & & $\theta($ broad band $)$ \\
\hline 45180 & 0 & $0_{0}^{0}$ \\
\hline 45720 & & $\nabla$ (main band $)+2 v($ triple bond stretch $)$ \\
\hline 45960 & 780 & $\theta / E^{a}$ \\
\hline 46210 & & $\bar{D}$ (broad band $)+v($ triple bond stretch $)$ \\
\hline 46430 & 1250 & $6_{0}^{1}$ \\
\hline 46840 & 1660 & $6_{0}^{1} 8_{0}^{1}$ \\
\hline 47230 & 2050 & $3_{0}^{1}$ \\
\hline 47510 & 2330 & $6_{0}^{2}$ \\
\hline 47960 & 2780 & $6_{0}^{2} 8_{0}^{1}$ \\
\hline 48340 & 3160 & $6_{0}^{2} 8_{0}^{2}$ \\
\hline
\end{tabular}

${ }^{a}$ An unassigned band belonging either to $\mathbb{E}-\not \chi$ (possibly perturbed by coupling to a $D-X^{x}$ transition) or to $D-X$.

D. Chain-coupling mechanisms

Studies on the synthesis of $\mathrm{HC}_{7} \mathrm{~N}$ and $\mathrm{HC}_{9} \mathrm{~N}$ in rare gas matrices suggested that the dominant path may consist in the attack of a (cyano)acetylenic radical on the other, intact precursor molecule. ${ }^{37,39}$ Consequently, the following scheme may be at work once $\mathrm{C}_{5} \mathrm{~N}^{*}$ becomes available:

$$
\begin{aligned}
& \mathrm{C}_{5} \mathrm{~N}^{\bullet}+\mathrm{CH}_{3} \mathrm{C}_{2} \mathrm{H} \rightarrow \mathbf{H C}_{7} \mathbf{N}+\mathrm{CH}_{3}{ }^{\bullet}, \\
& \mathrm{C}_{5} \mathrm{~N}^{\bullet}+\mathrm{CH}_{3} \mathrm{C}_{2} \mathrm{H} \rightarrow \mathbf{C H}_{3} \mathbf{C}_{7} \mathbf{N}+\mathrm{H}^{\bullet} .
\end{aligned}
$$


Although the above scheme is aimed at explaining the reactions occurring in cryogenic matrices, not in the interstellar medium, it is nevertheless in accordance with what Cherchneff et al. proposed for monocyanopolyacetylene formation in the circumstellar shell IRC $+10216 .^{60,61}$

The propyne photolysis may also take place, and then the reactions of $\mathrm{CH}_{3} \mathrm{C}_{2}{ }^{\bullet}$ could include:

$\mathrm{CH}_{3} \mathrm{C}_{2}{ }^{\bullet}+\mathrm{HC}_{5} \mathrm{~N} \rightarrow \mathbf{C H}_{3} \mathbf{C}_{7} \mathbf{N}+\mathrm{H}^{\bullet}$

Considering that the detection of products relied on phosphorescence, and that the applied excitation laser beam, not harmful to $\mathrm{HC}_{7} \mathrm{~N}$, efficiently photolyzed $\mathrm{CH}_{3} \mathrm{C}_{7} \mathrm{~N}$, it was not possible to propose even a rough estimation of relative yields for the reaction channels leading to the two discussed triacetylenic molecules. In this context, it is of interest to note, that our introductory experiments with a matrix-isolated, photolysed 1:1 mixture of $\mathrm{CH}_{3} \mathrm{C}_{2} \mathrm{H}$ and $\mathrm{HC}_{3} \mathrm{~N}$ led to approximately equally intense emissions from the two cyanodiacetylenes: $\mathrm{CH}_{3} \mathrm{C}_{5} \mathrm{~N}$ and $\mathrm{HC}_{5} \mathrm{~N}$. In this case, however, both photoproducts were stable during phosphorescence measurements.

The attempted reactions $\mathrm{CH}_{3} \mathrm{C}_{5} \mathrm{~N}+\mathrm{C}_{2} \mathrm{H}_{2}$ and $\mathrm{CH}_{3} \mathrm{C}_{3} \mathrm{~N}+\mathrm{C}_{2} \mathrm{H}_{2}$ did not yield any evidence for the elongation of a carbon chain. This suggest that it is easier to detach the methyl group from propyne (Eq. 1) than from a methylcyano(poly)yne molecule.

The discussed processes could possibly occur with a precursor molecule electronically excited rather than converted into a free radical (i.e. the separate dissociation step might not be distinguishable).

\section{CONCLUSIONS}


$\mathrm{CH}_{3} \mathrm{C}_{5} \mathrm{~N}$ and $\mathrm{CH}_{3} \mathrm{C}_{7} \mathrm{~N}$ molecules were successfully formed from respective smaller (cyano)acetylenic precursors in UV-stimulated cryogenic processes. Phosphorescence of $\mathrm{CH}_{3} \mathrm{C}_{7} \mathrm{~N}$, observed here for the first time, was strong enough to uncover the trace amounts of this compound, below the detection level for IR absorption. $\mathrm{HC}_{7} \mathrm{~N}$ and $\mathrm{CH}_{3} \mathrm{C}_{7} \mathrm{~N}$ (both products appear simultaneously) turned out to have almost coincident $a-\not$ origin wavelengths, as expected for large carbon-nitrogen chain species where the presence or absence of a terminating methyl group does not strongly affect the chromophore. Present studies provide good prospects for using the same approach to synthesize thus far unexplored $\mathrm{CH}_{3} \mathrm{C}_{9} \mathrm{~N}$ molecule; phosphorescence emissions of the tetraacetylenes $\mathrm{HC}_{9} \mathrm{~N}$ and $\mathrm{CH}_{3} \mathrm{C}_{9} \mathrm{~N}$ are however expected to be even more similar than those of their presently studied triacetylenic analogues.

Previous investigations of similar compounds $s^{37,38,40,57,62,63}$ were indicating the vibrational mode of the highest Raman activity as the one responsible for the leading progression in phosphorescence spectra. This trend seems to be preserved for $\mathrm{HC}_{7} \mathrm{~N}$ and $\mathrm{CH}_{3} \mathrm{C}_{7} \mathrm{~N}$.

The resemblance of $\mathrm{HC}_{7} \mathrm{~N}$ and $\mathrm{CH}_{3} \mathrm{C}_{7} \mathrm{~N}$ chromophores is well marked in their singlet-singlet transitions. As usual for the homologous series of chain compounds, the HOMO-LUMO (either $\pi$ $-\pi^{*}$ or $\mathrm{e}-\mathrm{e}^{*}$ ) energy gap decreases with the molecular length. ${ }^{64}$ Two main electronic systems could be distinguished: a fully allowed one and a strictly (for $\mathrm{HC}_{7} \mathrm{~N}$ ) or effectively (for $\mathrm{CH}_{3} \mathrm{C}_{7} \mathrm{~N}$ ) forbidden one. The forbidden $B-\not x$ transitions $\left(\Delta-\Sigma\right.$ and $\mathrm{E}-\mathrm{A}_{1}$, for $\mathrm{HC}_{7} \mathrm{~N}$ and $\mathrm{CH}_{3} \mathrm{C}_{7} \mathrm{~N}$, respectively) were rendered detectable through coupling with a chain-bending vibration of the $\mathrm{C}_{7} \mathrm{~N}$ chromophore. This bending, further coupled to a triple-bond stretching mode, promoted the main vibronic progression, recognized in the phosphorescence excitation spectrum. 


\begin{abstract}
SUPPORTING INFORMATION
Geometry of $\mathrm{HC}_{7} \mathrm{~N}$ and $\mathrm{CH}_{3} \mathrm{C}_{7} \mathrm{~N}$ in several electronic states; visualization of vibrational modes in selected electronic states of $\mathrm{HC}_{7} \mathrm{~N}$ and $\mathrm{CH}_{3} \mathrm{C}_{7} \mathrm{~N}$; phosphorescence spectra and newly observed band assignment for $\mathrm{HC}_{5} \mathrm{~N}$.
\end{abstract}

\title{
ACKNOWLEDGMENTS
}

This project was supported by the Polish National Science Centre, grant no. 2011/03/B/ST4/02763, French-Polish scientific cooperation programs Partenariat Hubert-Curien Polonium No. 27752QB (2012-2013), Polonium No. 33570RK (2015-2016), and PICS (20142016). U. Szczepaniak is a beneficiary of the French Government scholarship Bourse Eiffel, managed by Campus France, and of the project "Scholarships for PhD students of Podlaskie Voivodeship" - the project is co-financed by European Social Fund, Polish Government and Podlaskie Voivodeship. J.-C. Guillemin acknowledges the support from the Centre National d'Etudes Spatiales (CNES) and the French program Physique et Chimie du Milieu Interstellaire (PCMI) funded by the Conseil National de la Recherche Scientifique (CNRS) and CNES. Thanks are due to Prof. Tomonari Wakabayashi for sharing his data on electronic absorption of $\mathrm{HC}_{7} \mathrm{~N}$.

\section{REFERENCES}

(1) Turner, B. E. Detection of Interstellar Cyanoacetylene. Astrophvs. J. Lett. 1971, 163, L35. 
(2) Mauersberger, R.; Henkel, C.; Sage, L. J. Dense Gas in Nearby Galaxies. III - $\mathrm{HC}_{3} \mathrm{~N}$ as an Extragalactic Density Probe. Astron. Astrophys. 1990, 236, 63-68.

(3) Coustenis, A. The Atmospheric Structure of Titan from Voyager to Cassini. AGU Spring Meet. Abstr. 2007, 44.

(4) Bockelée-Morvan, D.; Lis, D. C.; Wink, J. E.; Despois, D.; Crovisier, J.; Bachiller, R.; Benford, D. J.; Biver, N.; Colom, P.; Davies, J. K.; et al. New Molecules Found in Comet C/1995 O1 (Hale-Bopp). Investigating the Link between Cometary and Interstellar Material. Astron.Astrophvs. 2000, 353, 1101-1114.

(5) Snell, R. L.; Schloerb, F. P.; Young, J. S.; Hjalmarson, A.; Friberg, P. Observations of HC ${ }_{3}$, $\mathrm{HC}_{5} \mathrm{~N}$, and $\mathrm{HC}_{7} \mathrm{~N}$ in Molecular Clouds. Astrophys.J. 1981, 244, 45-53.

(6) Truong-Bach; Graham, D.; Nguyen-Q-Rieu. $\mathrm{HC}_{9} \mathrm{~N}$ from the Envelopes of IRC+10216 and CRL:2688. Astron. Astronhys. 1993, 277, 133.

(7) Broten, N. W.; MacLeod, J. M.; Avery, L. W.; Friberg, P.; Hjalmarson, A.; Hoglund, B.; Irvine, W. M. The Detection of Interstellar Methylcyanoacetylene. Astrophvs__. 1984, 276, L25.

(8) Belloche, A.; Müller, H. S. P.; Menten, K. M.; Schilke, P.; Comito, C. Complex Organic Molecules in the Interstellar Medium: IRAM 30 M Line Survey of Sagittarius B2(N) and (M). Astron. Astrophvs. 2013, 559, A47.

(9) Snyder, L. E.; Hollis, J. M.; Jewell, P. R.; Lovas, F. J.; Remijan, A. Confirmation of Interstellar Methylcyanodiacetylene $\left(\mathrm{CH}_{3} \mathrm{C}_{5} \mathrm{~N}\right)$. Astrophvs. J. 2006, 647 (1), 412. 
(10) Quan, D.; Herbst, E. Possible gas-phase syntheses for seven neutral molecules studied recently with the Green Bank Telescope. Astron. Astrophys. 2007, 10, 474.

(11) Herbst, E.; Leung, C. M. Gas-Phase Production of Complex Hydrocarbons, Cyanopolyynes, and Related Compounds in Dense Interstellar Clouds. Astrophys. J. Suppl. Ser. 1989, 69, 271.

(12) Markwick, A. J.; Millar, T. J.; Charnley, S. B. On the Abundance Gradients of Organic Molecules along the TMC-1 Ridge. Astrophvs. J. 2000, 535 (1), 256.

(13) Kalvāns, J.; Shmeld, I. Subsurface Chemistry of Mantles of Interstellar Dust Grains in Dark Molecular Cores. Astron. Astrophys. 2010, 521, A37.

(14) Vuitton, V.; Yelle, R. V.; McEwan, M. J. Ion Chemistry and N-Containing Molecules in Titan’s Upper Atmosphere. Icarus 2007, 191 (2), 722-742.

(15) Loison, J. C.; Hébrard, E.; Dobrijevic, M.; Hickson, K. M.; Caralp, F.; Hue, V.; Gronoff, G.; Venot, O.; Bénilan, Y. The Neutral Photochemistry of Nitriles, Amines and Imines in the Atmosphere of Titan. Icarus 2015, 247, 218-247.

(16) Kerisit, N.; Rouxel, C.; Colombel-Rouen, S.; Toupet, L.; Guillemin, J.-C.; Trolez, Y. Synthesis, Chemistry, and Photochemistry of Methylcyanobutadiyne in the Context of Space Science. J. Org. Chem. 2016.

(17) Sheridan, J.; Thomas, L. F. Microwave Spectrum of Methyl-Cyanoacetylene. Nature 1954, 174 (4434), 798-798.

(18) Tubino, R.; Dellepiane, G.; Zerbi, G. Vibrational Spectrum and Vibro $\square$ Rotational Analysis of Cyanopropyne. L.Chem.Phvs. 1969, 50 (2), 621-627. 
(19) Bossis, G. Le Moment Dipolaire et l'absorption en Infrarouge Lointain du Cyanopropyne, Existence d'une Tres Forte Contribution des Dipoles Temporaires Induits. Mol. Phys. 1976, 31 (6), 1897-1908.

(20) Dello Russo, N.; Khanna, R. K. Laboratory Infrared Spectroscopic Studies of Crystalline Nitriles with Relevance to Outer Planetary Systems. carus 1996, 123 (2), 366-395.

(21) Khlifi, M.; Raulin, F. Infrared Intensities and Frequencies of 2-Butynenitrile: Application to the Atmosphere of Titan. Spectrochim.Acta Part Mol.Spectrosc. 1991, 47 (2), 171-176.

(22) Bruston, P.; Poncet, H.; Raulin, F.; Cossart-Magos, C.; Courtin, R. UV Spectroscopy of Titan's Atmosphere, Planetary Organic Chemistry, and Prebiological Synthesis: I. Absorption Spectra of Gaseous Propynenitrile and 2-Butynenitrile in the 185- to 250-nm Region. Lcarus 1989, 78 (1), 38-53.

(23) Bieri, G.; Heilbronner, E.; Hornung, V.; Kloster-Jensen, E.; Maier, J. P.; Thommen, F.; Niessen, W. von. Electronic States of Substituted Haloacetylene and Cyanoacetylene Radical Cations. Chem.Phys. 1979, 36 (1), 1-14.

(24) Lamarre, N.; Gans, B.; Vieira Mendes, L. A.; Gronowski, M.; Guillemin, J.-C.; De Oliveira, N.; Douin, S.; Chevalier, M.; Crépin, C.; Kołos, R.; et al. Excited Electronic Structure of Methylcyanoacetylene Probed by VUV Fourier-Transform Absorption Spectroscopy. L. Ouant. Spectrosc. Radiat.Transf. 2016, 182, 286-295.

(25) Alexander, A. J.; Kroto, H. W.; Maier, M.; Walton, D. R. M. The Microwave Spectra of Symmetric Top Polyacetylenes. L.Mol. Spectrosc. 1978, 70 (1), 84-94. 
(26) Chen, W.; Grabow, J.-U.; Travers, M. J.; Munrow, M. R.; Novick, S. E.; McCarthy, M. C.; Thaddeus, P. Microwave Spectra of the Methylcyanopolyynes $\mathrm{CH}_{3}(\mathrm{CC})_{n} \mathrm{CN}, \mathrm{n}=2,3,4$, 5. J.Mol. Spectrosc. 1998, 192 (1), 1-11.

(27) Montero-Campillo, M. M.; Mó, O.; Yáñez, M.; Benidar, A.; Rouxel, C.; Kerisit, N.; Trolez, Y.; Guillemin, J.-C. Gas-Phase Infrared Spectroscopy of Substituted Cyanobutadiynes: Roles of the Bromine Atom and Methyl Group as Substituents. ChemPhvsChem 2016, 17 (7), 1018-1024.

(28) Szczepaniak, U.; Turowski, M.; Custer, T.; Gronowski, M.; Kerisit, N.; Trolez, Y.; Kołos, R. Infrared and Raman Spectroscopy of Methylcyanodiacetylene $\left(\mathrm{CH}_{3} \mathrm{C}_{5} \mathrm{~N}\right)$. ChemPhysChem 2016, 17 (19), 3047-3054.

(29) Turowski, M.; Szczepaniak, U.; Custer, T.; Gronowski, M.; Kołos, R. Electronic Spectroscopy of Methylcyanodiacetylene $\left(\mathrm{CH}_{3} \mathrm{C}_{5} \mathrm{~N}\right)$. ChemPhvsChem 2016, 17 (24), 40684078.

(30) Kerisit, N.; Toupet, L.; Trolez, Y.; Guillemin, J.-C. Methylcyanobutadiyne: Synthesis, XRay Structure and Photochemistry; Towards an Explanation of Its Formation in the Interstellar Medium. Chem. Eur.J. 2013, 19 (52), 17683-17686.

(31) Bohlmann, F.; Mannhardt, H.-J. Polyacetylenverbindungen, XVIII. Mitteil.: Über die Lichtabsorption von Polyin-Carbonsäurenitrilen. Chem. Ber. 1956, 89 (10), 2268-2272.

(32) Thaddeus, P.; McCarthy, M. C.; Travers, M. J.; Gottlieb, C. A.; Chen, W. New Carbon Chains in the Laboratory and in Interstellar Space. Earadav Discuss. 1998, 109, 121-135. 
(33) McCarthy, M. C.; Chen, W.; Travers, M. J.; Thaddeus, P. Microwave Spectra of 11 Polyyne Carbon Chains. Astrophvs.J.Suppl.Ser. 2000, 129 (2), 611.

(34) Arnau, A.; Tuñón, I.; Andrés, J.; Silla, E. Theoretical Rotational Constants of $\mathrm{MeC}_{\mathrm{n}} \mathrm{N}$ Species. Chem. Phvs. Lett. 1990, 166 (1), 54-56.

(35) Woon, D. E.; Herbst, E. Quantum Chemical Predictions of the Properties of Known and Postulated Neutral Interstellar Molecules. Astrophvs.J.Suppl.Ser. 2009, 185 (2), 273.

(36) Coupeaud, A.; Kołos, R.; Couturier-Tamburelli, I.; Aycard, J. P.; Piétri, N. Photochemical Synthesis of the Cyanodiacetylene $\mathrm{HC}_{5} \mathrm{~N}$ : A Cryogenic Matrix Experiment. J. Phys. Chem. A 2006, $110(7), 2371-2377$.

(37) Couturier-Tamburelli, I.; Piétri, N.; Crépin, C.; Turowski, M.; Guillemin, J.-C.; Kołos, R. Synthesis and Spectroscopy of Cyanotriacetylene $\left(\mathrm{HC}_{7} \mathrm{~N}\right)$ in Solid Argon. J. Chem. Phys. 2014, 140 (4), 044329.

(38) Crépin, C.; Turowski, M.; Ceponkus, J.; Douin, S.; Boyé-Péronne, S.; Gronowski, M.; Kołos, R. UV-Induced Growth of Cyanopolyyne Chains in Cryogenic Solids. Phys. Chem. Chem. Phvs. PCCP 2011, 13 (37), 16780-16785.

(39) Szczepaniak, U.; Crépin, C.; Gronowski, M.; Chevalier, M.; Guillemin, J.-C.; Turowski, Michał; Custer, T.; Kołos, R. Cryogenic Photochemical Synthesis and Electronic Spectroscopy of Cyanotetraacetylene. L.Phvs. Chem.A 2017, 121 (39), 7374-7384.

(40) Turowski, M.; Crépin, C.; Douin, S.; Kołos, R. Formation and Spectroscopy of Dicyanotriacetylene $\left(\mathrm{NC}_{8} \mathrm{~N}\right)$ in Solid Kr. L. Phvs. Chem.A 2014, 119 (11), 2701-2708. 
(41) Fahr, A.; Laufer, A. H. UV-Absorption Spectra of the Radical Transients Generated from the 193-nm Photolysis of Allene, Propyne, and 2-Butyne. J. Phys. Chem. A 2005, 109 (11), 2534-2539.

(42) Alnama, K.; Boyé-Péronne, S.; Douin, S.; Innocenti, F.; O’Reilly, J.; Roche, A.-L.; Shafizadeh, N.; Zuin, L.; Gauyacq, D. Photolysis of Allene and Propyne in the 7-30eV Region Probed by the Visible Fluorescence of Their Fragments. J. Chem. Phys. 2007, 126 (4), 044304.

(43) Wakabayashi, T.; Saikawa, M.; Wada, Y.; Minematsu, T. Isotope Scrambling in the Formation of Cyanopolyynes by Laser Ablation of Carbon Particles in Liquid Acetonitrile. Carbon 2012, 50 (1), 47-56.

(44) Cataldo, F. Monocyanopolyynes from a Carbon Arc in Ammonia: About the Relative Abundance of Polyynes Series Formed in a Carbon Arc and Those Detected in the Circumstellar Shells of AGB Stars. Int. J.Astrobiol. 2006, 5 (01), 37-45.

(45) Cataldo, F. Polyynes and Cyanopolyynes: Their Synthesis with the Carbon Arc Gives the Same Abundances Occurring in Carbon-Rich Stars. Orig. Life Evol. Biospheres 2006, 36 (56), $467-475$.

(46) Forte, G.; D’Urso, L.; Fazio, E.; Patanè, S.; Neri, F.; Puglisi, O.; Compagnini, G. The Effects of Liquid Environments on the Optical Properties of Linear Carbon Chains Prepared by Laser Ablation Generated Plasmas. Appl. Surf.Sci. 2013, 272, 76-81.

(47) Trolez, Y.; Guillemin, J.-C. Synthesis and Characterization of 2,4-Pentadiynenitrile-A Key Compound in Space Science. Angew. Chem. Int. Ed. 2005, 44 (44), 7224-7226. 
(48) Miller, F. A.; Lemmon, D. H. The Infrared and Raman Spectra of Dicyanodiacetylene, $\mathrm{N} \equiv \mathrm{C}-\mathrm{C} \equiv \mathrm{C}-\mathrm{C} \equiv \mathrm{C}-\mathrm{C} \equiv \mathrm{N}$. Spectrochim. Acta Part Mol. Spectrosc. 1967, 23 (5), 1415-1423.

(49) Frisch, M. J.; Trucks, G. W.; Schlegel, H. B.; Scuseria, G. E.; Robb, M. A.; Cheeseman, J. R.; Scalmani, G.; Barone, V.; Mennucci, B.; Petersson, G. A.; et al. Gaussian 09; Gaussian, Inc.: Wallingford, CT, USA, 2009.

(50) Parr, R. G.; Weitao, Y. Density-Functional Theory of Atoms and Molecules; Oxford University Press, 1989.

(51) Perdew, J. P.; Burke, K.; Wang, Y. Generalized Gradient Approximation for the Exchange-Correlation Hole of a Many-Electron System. Phvs. Rev. B 1996, 54 (23), 1653316539.

(52) Dunning, T. H. J. Gaussian Basis Sets for Use in Correlated Molecular Calculations. I. The Atoms Boron through Neon and Hydrogen. L.Chem. Phys. 1989, 90 (2), 1007-1023.

(53) Kendall, R. A.; Jr, T. H. D.; Harrison, R. J. Electron Affinities of the First $\square$ row Atoms Revisited. Systematic Basis Sets and Wave Functions. L.Chem. Phvs. 1992, 96 (9), 67966806.

(54) Job, V. A.; King, G. W. The Electronic Spectrum of Cyanoacetylene: Part II. Analysis of the 2300-Å System. L.Mol. Spectrosc. 1966, 19 (1-4), 178-184.

(55) Turowski, M.; Crépin, C.; Gronowski, M.; Guillemin, J.-C.; Coupeaud, A.; CouturierTamburelli, I.; Piétri, N.; Kołos, R. Electronic Absorption and Phosphorescence of Cyanodiacetylene. J.Chem. Phys. 2010, 133 (7), 074310. 
(56) McCarthy, M. C.; Levine, E. S.; Apponi, A. J.; Thaddeus, P. Experimental Structures of the Carbon Chains $\mathrm{HC}_{7} \mathrm{~N}, \mathrm{HC}_{9} \mathrm{~N}$, and $\mathrm{HC}_{11} \mathrm{~N}$ by Isotopic Substitution. J. Mol. Spectrosc. 2000, 203 (1), 75-81.

(57) Turowski, M. Niskotemperaturowe Badania Fotochemii i Spektroskopii Cyjanoacetylenów o Znaczeniu Astrofizycznym. PhD Dissertation, Institute of Physical Chemistry, Polish Academy of Sciences: Warsaw, Poland, 2012.

(58) Turowski, M.; Crépin, C.; Douin, S.; Gronowski, M.; Couturier-Tamburelli, I.; Piétri, N.; Wasiak, A.; Kołos, R. Low Temperature Raman Spectra of Cyanobutadiyne $\left(\mathrm{HC}_{5} \mathrm{~N}\right)$. Vib. Spectrosc. 2012, 62, 268-272.

(59) Kołos, R., unpublished result, 2017.

(60) Cherchneff, I.; Glassgold, A. E. The Formation of Carbon Chain Molecules in IRC +10216. Astrophvs. J.Lett. 1993, 419, L41.

(61) Cherchneff, I.; Glassgold, A. E.; Mamon, G. A. The Formation of Cyanopolyyne Molecules in IRC + 10216. Astrophys.J. 1993, 410, 188-201.

(62) Chang, J.-W.; Lee, Y.-P. The $\mathrm{C}_{2} \mathrm{~N}_{2} \mathrm{a}^{3} \Sigma_{u}^{+} \rightarrow \mathrm{X}^{1} \Sigma_{g}^{+}$Chemiluminescence in Matrices. $J$. Mol.Struct. 1987, 157 (1-3), 155-165.

(63) Turowski, M.; Crépin, C.; Couturier-Tamburelli, I.; Piétri, N.; Kołos, R. LowTemperature Phosphorescence of Dicyanoacetylene in Rare Gas Solids. Low Temp. Phys. 2012, $38(8), 723-726$. 
(64) Connors, R. E.; Roebber, J. L.; Weiss, K. Vacuum Ultraviolet Spectroscopy of Cyanogen and Cyanoacetylenes. L.Chem. Phvs. 1974, 60 (12), 5011-5024. 


\section{TOC Graphic}

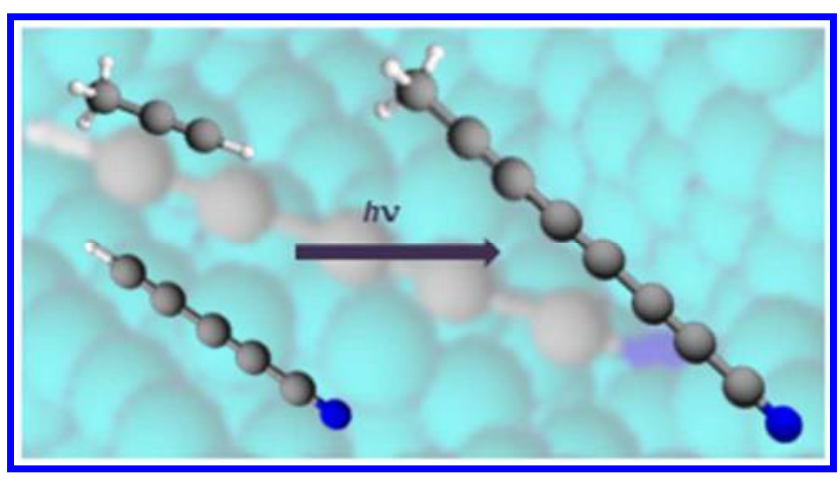

20 
$\tilde{B}^{1} \mathrm{E} 111.10$

$\tilde{E}^{1} A_{1} 111.28$

$\tilde{a}^{3} A^{\prime} 111.32$

$\begin{array}{cccccccccc}\tilde{X}^{1} \mathrm{~A}_{1} & 109.3 & 144.3 & 121.2 & 134.8 & 122.0 & 134.2 & 121.7 & 135.7 & 115.9 \\ \tilde{B}^{1} \mathrm{E} & +0.2 & -0.8 & +2.7 & -4.3 & +5.3 & -5.5 & +4.7 & -3.2 & +1.8 \\ \tilde{E}^{1} \mathrm{~A}_{1} & +0.6 & -1.5 & +2.3 & +0.1 & +1.5 & +0.4 & +2.2 & -1.3 & +2.0 \\ \tilde{a}^{3} \mathrm{~A}^{\prime} & +0.2 & -0.5 & +2.9 & -4.7 & +6.1 & -6.4 & +5.4 & -3.4 & +2.0 \\ & +0.1 & & & & & & & & \end{array}$

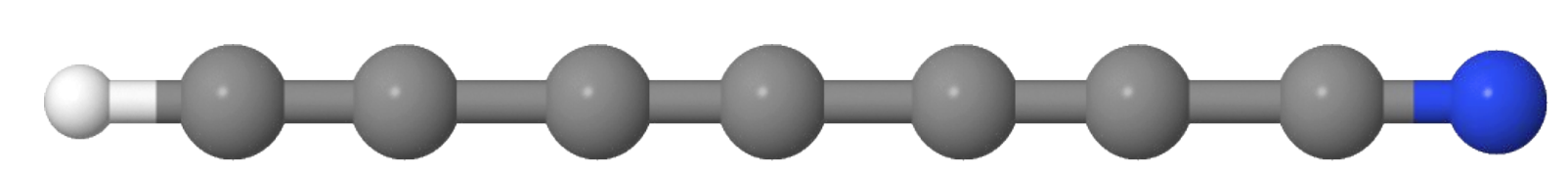

$\tilde{X}^{1} \Sigma^{+} \begin{array}{llllllll}1.0570(4) & 1.2101(6) & 1.3610(9) & 1.1241(19) & 1.3616(27) & 1.2149(20) & 1.3657(9) & 1.1611(6)\end{array}$

$\begin{array}{llllllll}106.4 & 120.8 & 135.0 & 121.8 & 134.3 & 121.6 & 135.7 & 115.9\end{array}$

$\begin{array}{lllllllll}\tilde{B}^{1} \Delta & 0.0 & +2.7 & -4.3 & +5.5 & -5.7 & +4.9 & -3.2 & +1.8\end{array}$

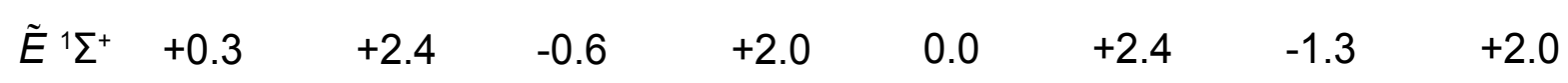

$\begin{array}{lllllll}\tilde{a}^{3} \Sigma^{+} & 0.0 & +3.0 & -4.8^{\text {ACS Paragon Plus Environment }}+6.3^{-6.5^{-3}}+5.4 & -3.3 & +1.8\end{array}$




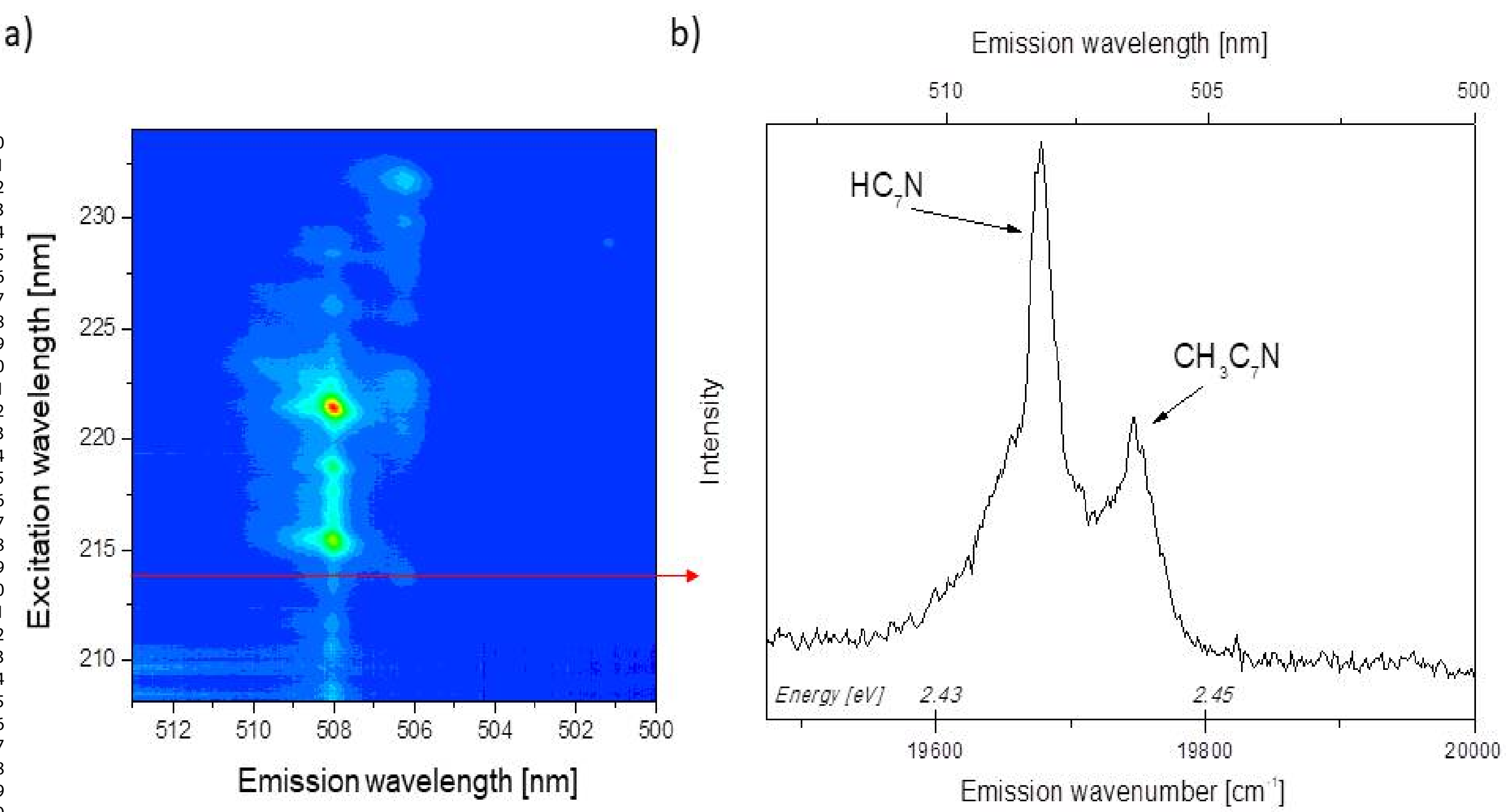




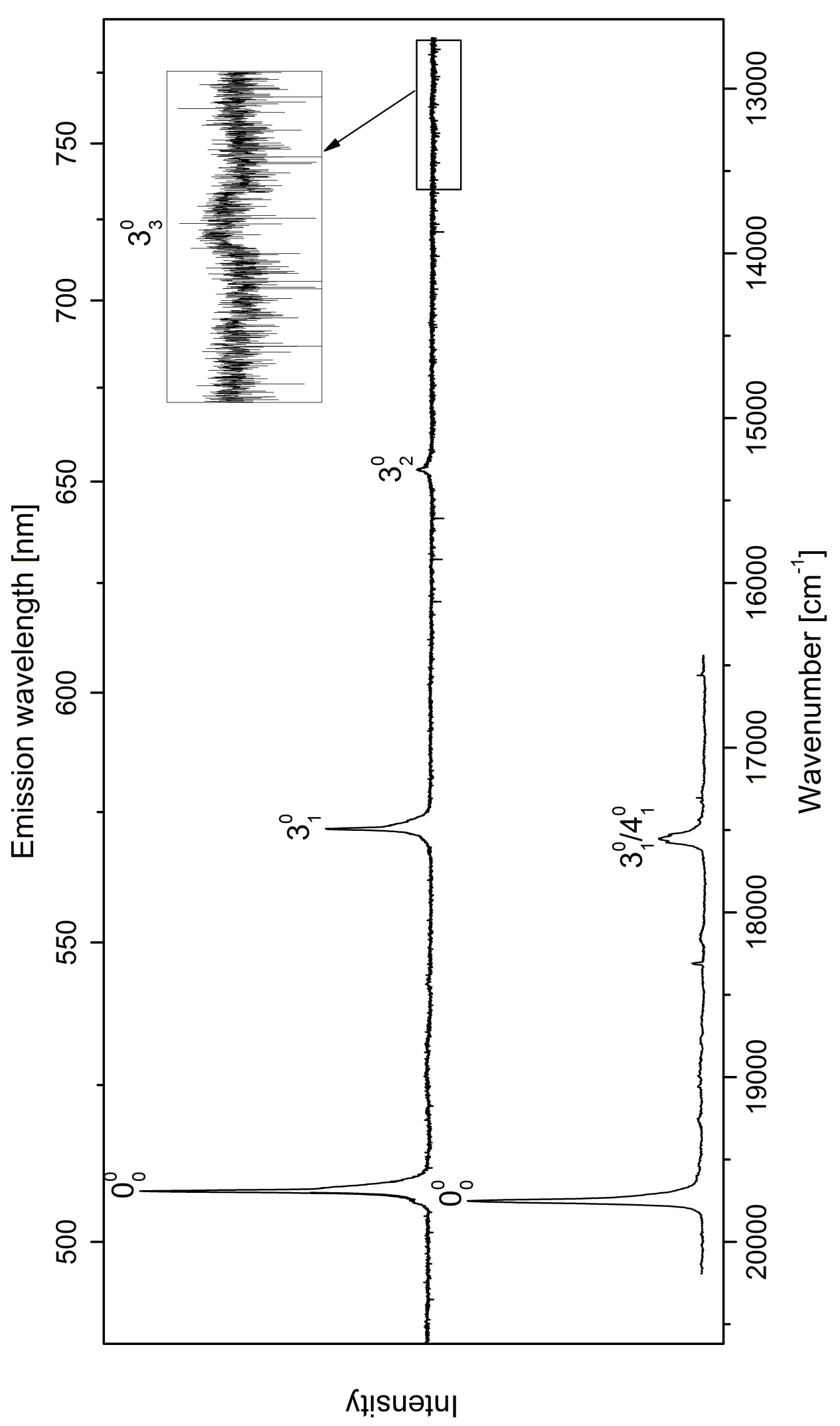




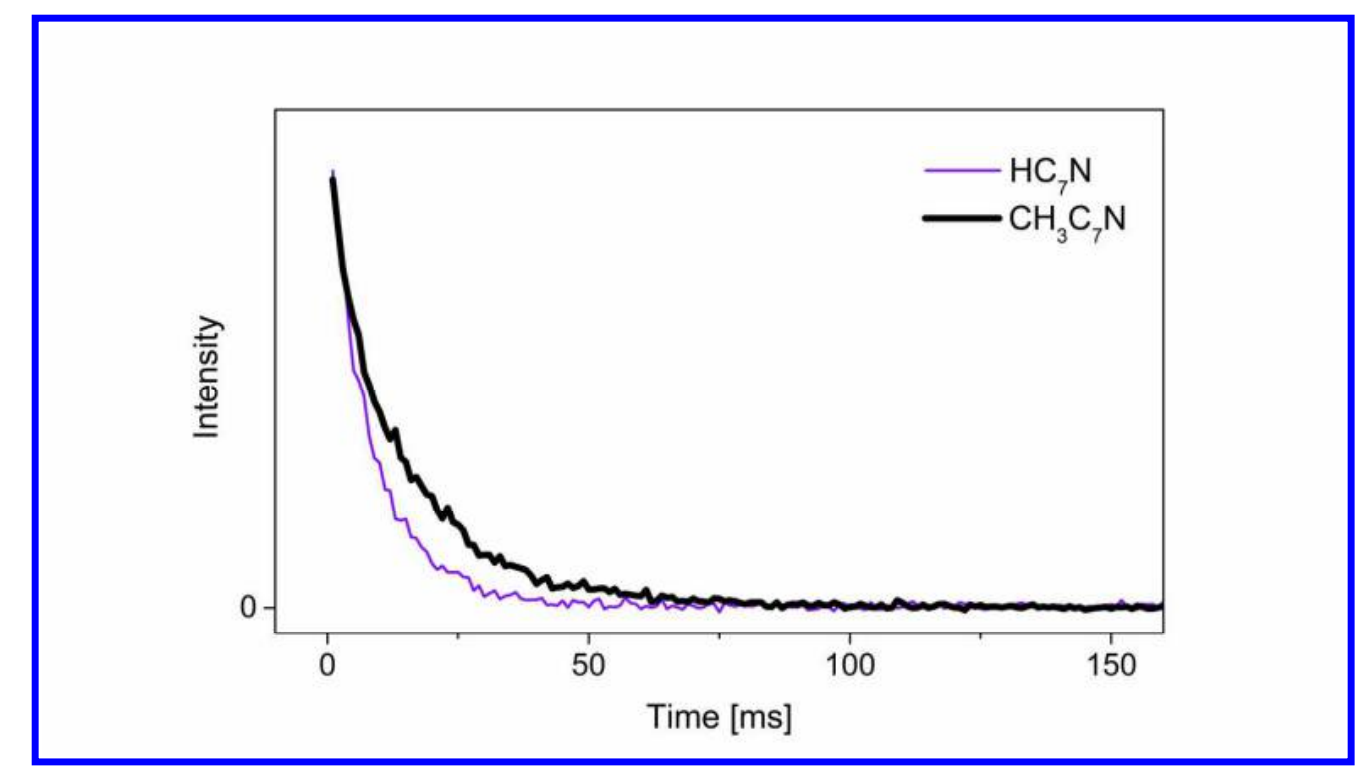

Figure 4.

$199 \times 112 \mathrm{~mm}(300 \times 300 \mathrm{DPI})$ 


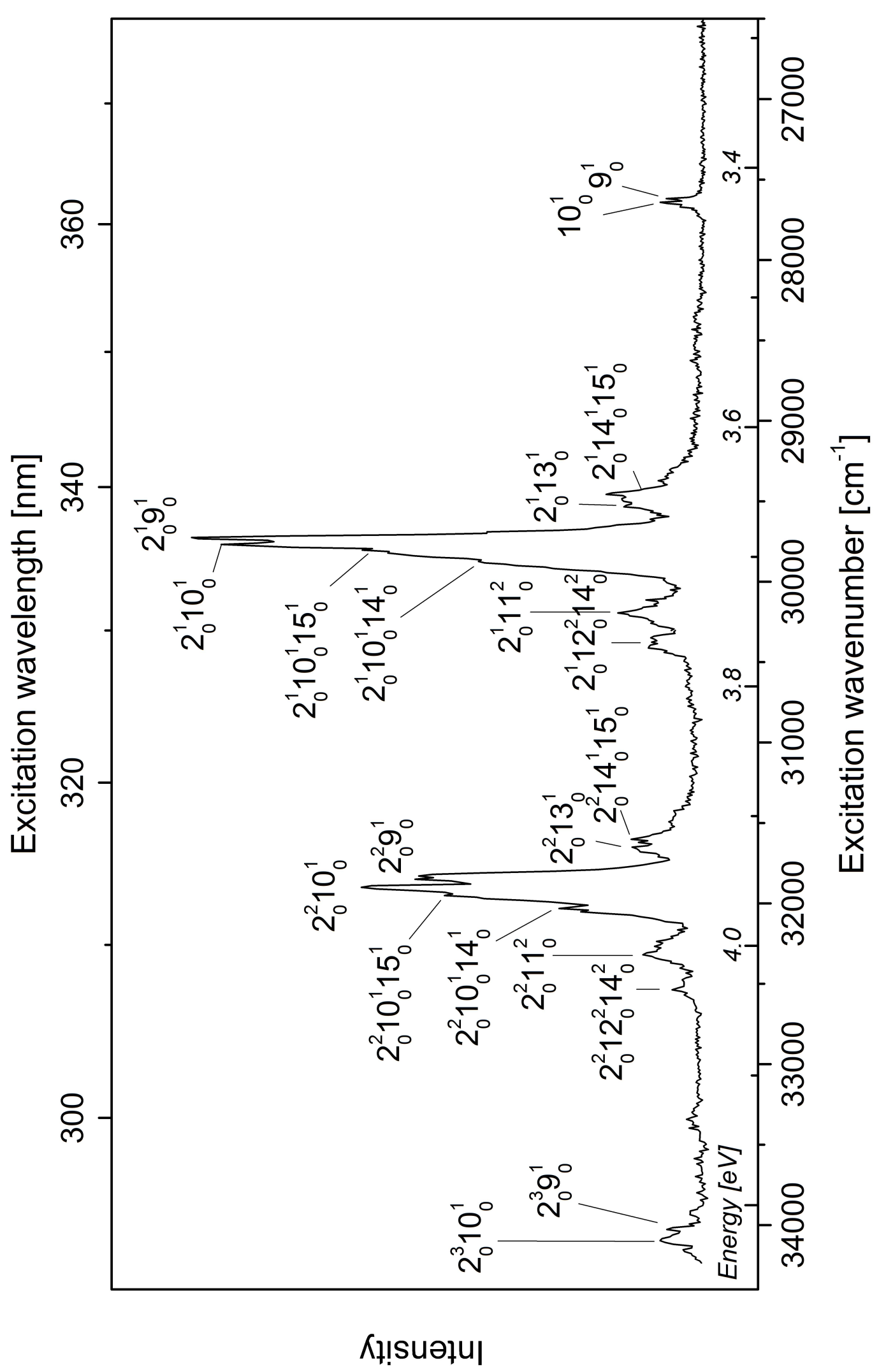




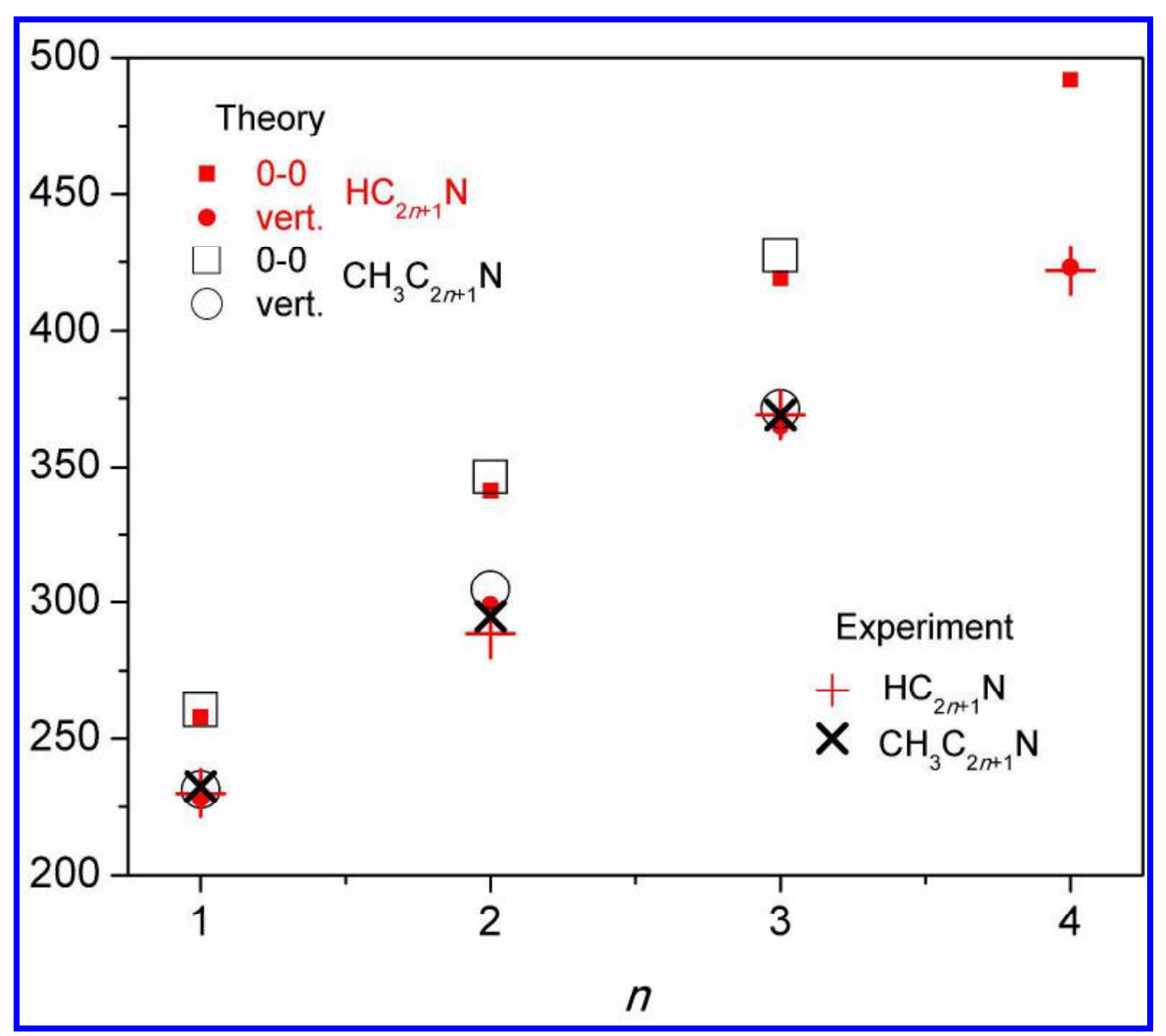

Figure 6.

$289 \times 257 \mathrm{~mm}(300 \times 300$ DPI $)$ 


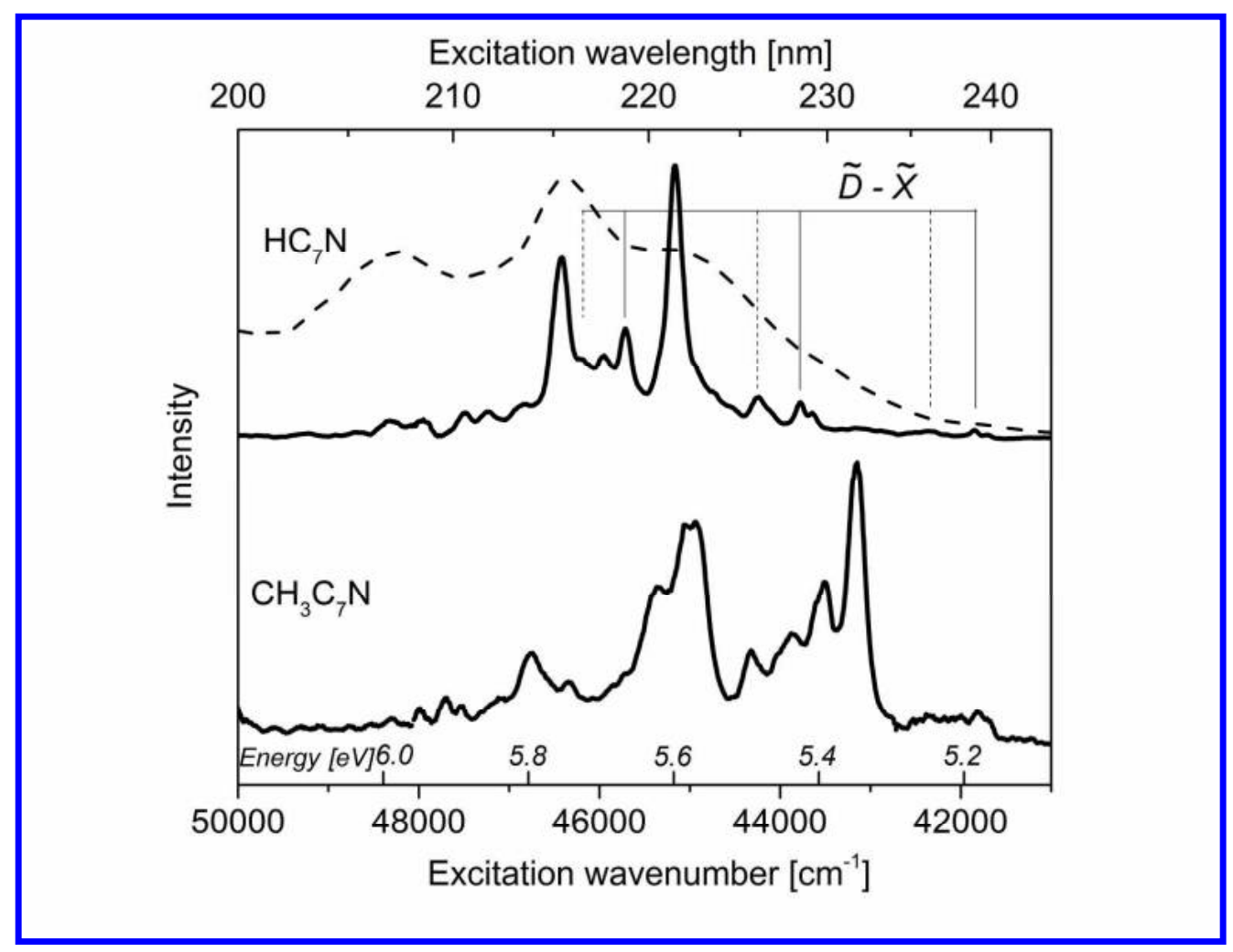

Figure 7.

$208 \times 159 m m(300 \times 300$ DPI $)$ 


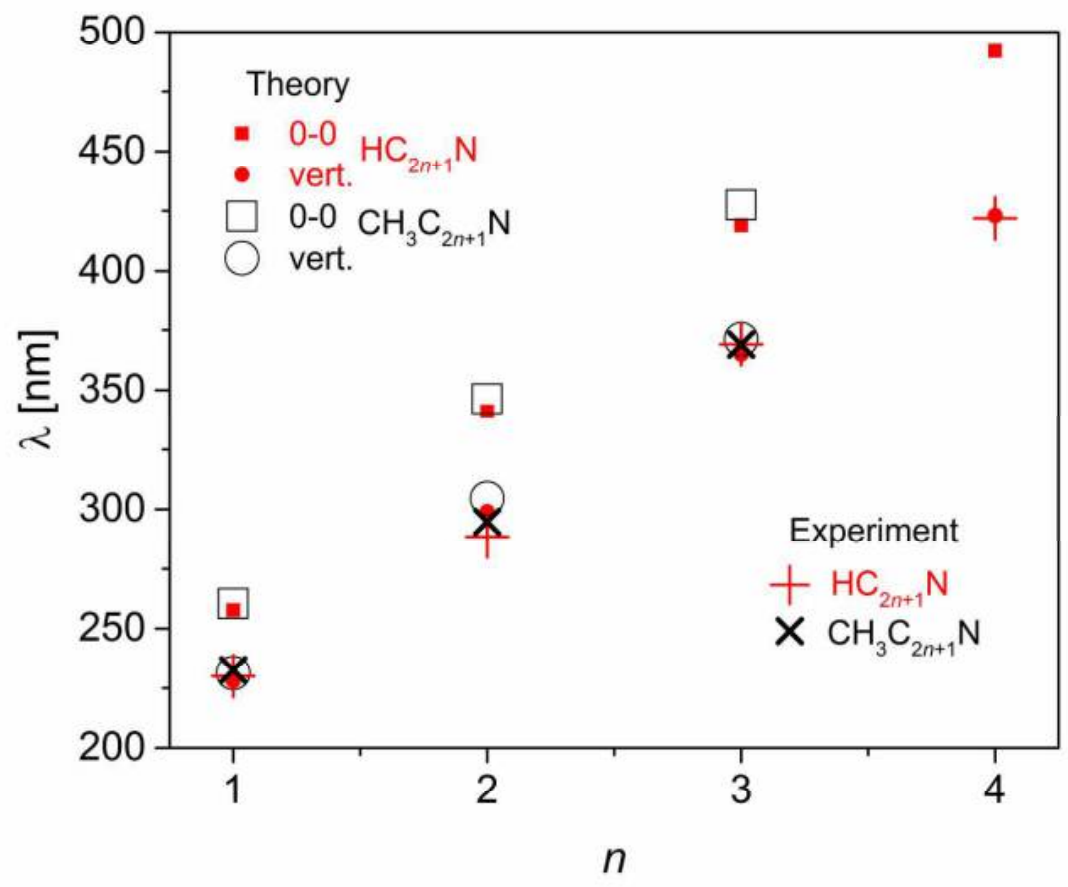

Figure 6.

208x159mm (300 x 300 DPI) 